NBSIR 82-2600

\title{
A Cost-Conscious Guide to Fire Safety in Health Care Facilities
}

U.S. DEPARTMENT OF COMMERCE

National Bureau of Standards

National Engineering Laboratory

Center for Applied Mathematics

Washington, DC 20234

December 1982

Sponsored by:

U.S. DEPARTMENT OF COMMERCE

National Bureau of Standards

National Engineering Laboratory

Center for Fire Research

Washington, DC 20234

$-$

and

100 Department of Health and Human Services

.456

Washington, DC 20201 



\section{A COST-CONSCIOUS GUIDE TO FIRE SAFETY IN HEALTH CARE FACILITIES}

Robert E. Chapman

U.S. DEPARTMENT OF COMMERCE

National Bureau of Standards

National Engineering Laboratory

Center for Applied Mathematics

Washington, DC 20234

December 1982

\section{Sponsored by:}

U.S. DEPARTMENT OF COMMERCE

National Bureau of Standards

National Engineering Laboratory

Center for Fire Research

Washington, DC 20234

and

Department of Health and Human Services

Washington, DC 20201

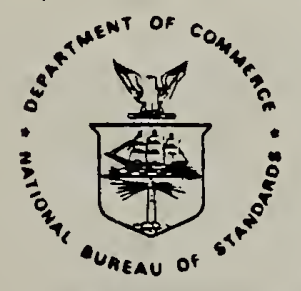

U.S. DEPARTMENT OF COMMERCE, Malcolm Baldrige, Secretary NATIONAL BUREAU OF STANDARDS, Ernest Ambler, Director 



\section{PREFACE}

This research was conducted under the sponsorship of the Center for Fire Research and the Department of Health and Human Services by the Operations Research Division, Center for Applied Mathematics, National Engineering Laboratory, National Bureau of Standards.

This report is, a product of the Fire and Life Safety Program. This program is a joint Department of Health and Human Services (HHS) and National Bureau of Standards (NBS) effort directed at the development of rational, technically sound solutions to fire safety problems in health care facilities. In addition to the types of work described in this report, the foint HHS/NBS program has produced products in the areas of decision analysis, fire and smoke detection, smoke movement and control, automatic extinguishment, and behavior of institutional and other populations in fire situations.

This report, intended for use by building managers and engineers, outlines a computer program which utilizes mathematical optimization techriques to identify the least-cost means of upgrading health care facilities to compliance with the Life Safety Code. The program uses the "optimal". solution as a reference point from which 10 to 20 compliance strategles based on design considerations are generated. The computer program is intended to be used as a management tool to facilitate the design selection process by providing both information on relative costs and a chance to match common compliance strategies across all parts of the building.

The author would like to acknowledge the significant contributions made to this study by Mssrs. Harold E. Nelson and A. Jeffery Shibe of the Center for Fire Research. Their review of the document and suggestions for improving the treatment of certain topics in the paper were most useful. Appreciation is also extended to $\mathrm{Mr}$. Richard $\mathrm{W}$. Bukowski of the Center for Fire Research, who designed the worksheet for collecting the input data required to exercise the computer program, and $\mathrm{Mr}$. Phillip T. Chen, formerly with the Center for Building Technology, who made the first attempts at integrating the relevant engineering issues with the formal optimization techniques used by the program. Special appreciation is extended to Mr. William G. Hall of the Center for Applied Mathematics, whose stimulating discussions provided guidance and encouragement throughout this effort. 
This report outlines a computer program which, using the Fire Safety Evaluation System as its nucleus, employs mathematical optimization technlques to 1dentify the least-cost means of achleving a set of prescribed levels of fire safety in health care fac1litles. The fire Safety Evaluation System 7 sis9 developed by the Center for Fire Research at the National Bureau of Standards, s.i through support from the Department of Health and Human Services, helps decision makers by determining how combinations of several widely accepted fire safety systems can be used to ptovide a level bf bafety equivalent to als

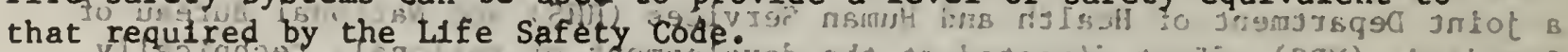

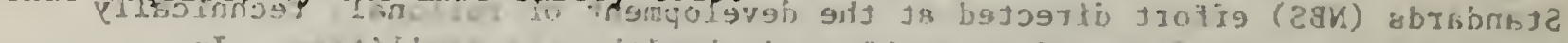

The econonIc consequences associated with the Qise the Fite safety

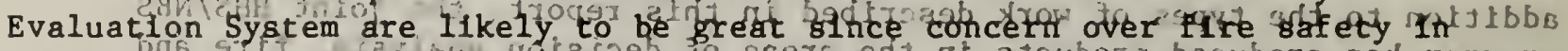

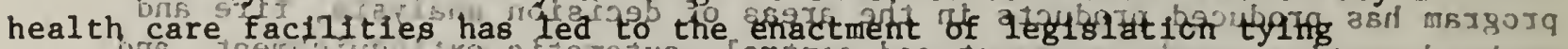

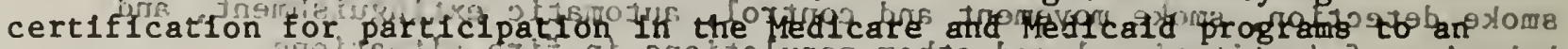

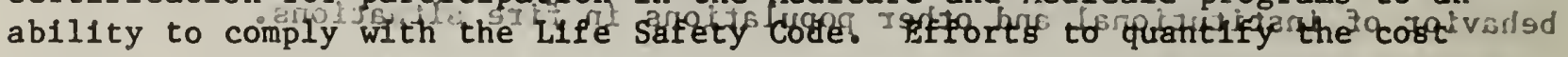
savings attributable to the use of a performance-oriented system over that of prescriptive compliance are simplified by noting that each of the hullding safety features used in the Fre saftet

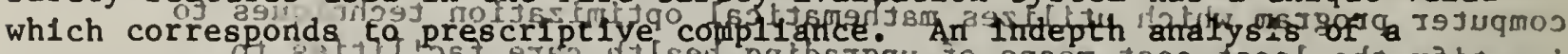

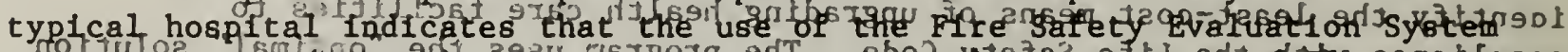

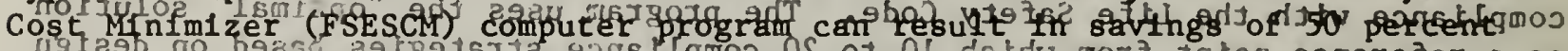

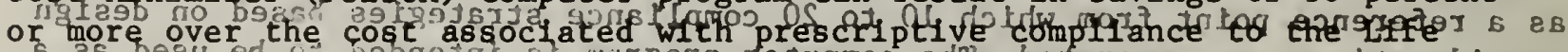

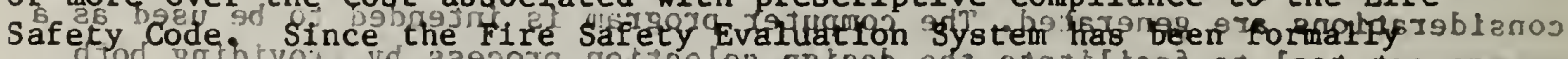
adopted into the 1981 edition of the tite sate ty " Colte, J

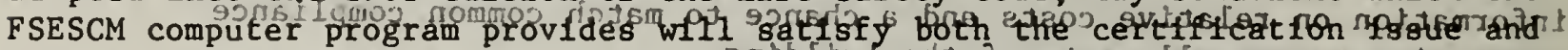

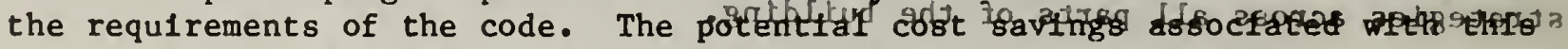
procedure are therefore of particular importance to those health care facilities which have a strong dependence on revenues from the Medicare and Medicald programs.

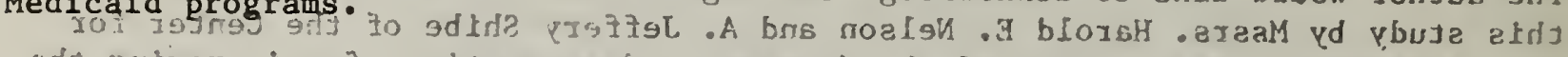

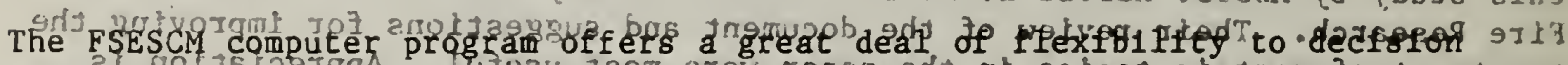

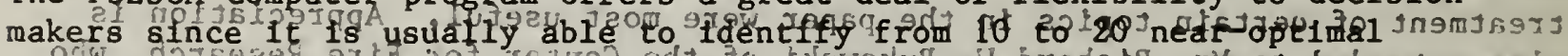

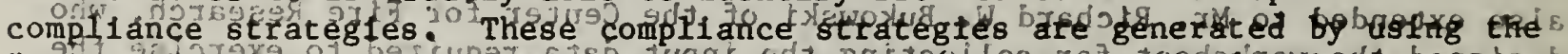

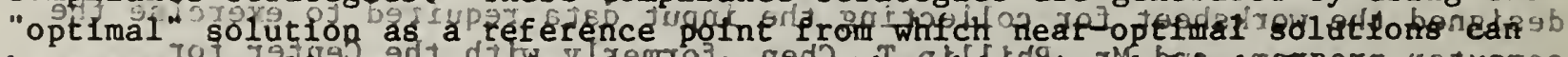

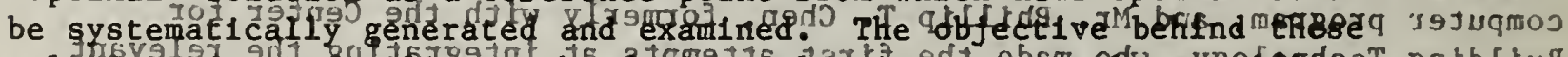

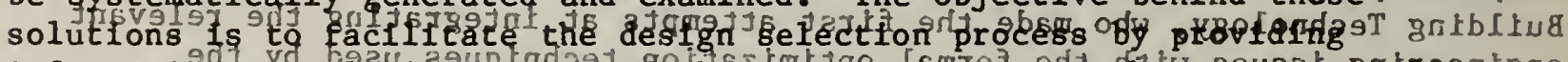

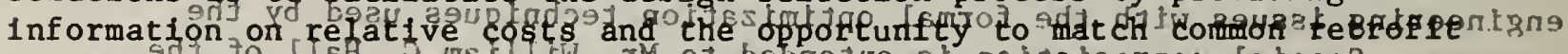

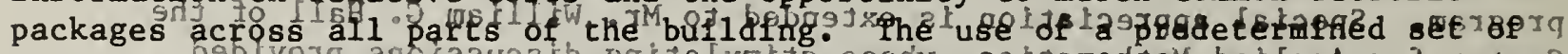

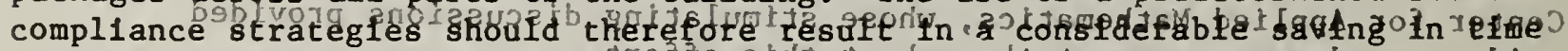

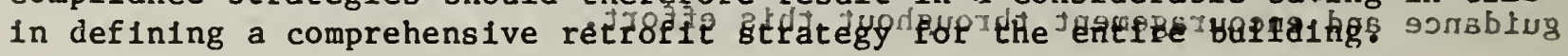

A cost study of a typical hospital is used to indicate the tremendous potential for reducing code compliance costs without compromising the safety and well-belng of persons housed in health care facilitles. Although the savings in retrofit costs which will accrue to the nation's stock of health care facilities is substantial, it is expected that savings will vary considerably as a function of the facility type, 1ts condition, and its operational characteristics. Since the design places certain constraints on 
the retrofit process, the data required from the engineer in the fleld are organized in a manner which explicitly introduces relevant engineering issues into the cost minimization problem. The cost estimates produced by the procedure should permit the engineering staff to quickly identify several compliance strategies which best reflect the specific attributes or peculiarities of the facility. Since the compliance strategles are built around those items deemed most important from an engineering viewpolnt, their inclusion should simplify the problem of assessing the impacts of non-construction costs on the retrofit decision.

The FSESCM computer program is written in FORTRAN, a widely used language for scientific applications. The program has been thoroughly tested for ease of use and flexibility. For example, the program contains a series of user options which make it possible to alter the cost of any retrofit, preclude a ret.rofit, force a retrofit to be included, or demand a level of safety different from that required by the Life Safety Code. The program conforms to the major programming standards (FIPS 69 and ANSI X3.9-1978) and is executable on any standard system of adequate size. Two companion reports are available which give step-by-step instructions for setting up and running the program on the user's computer system. 
PREFACE....................................... 111

EXECUTIVE SUMMARY.................................. 1v

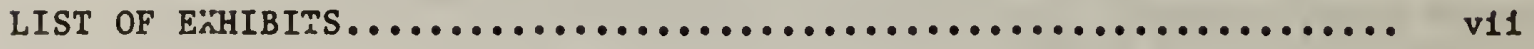

LIST OF FIGURES.................................... v111

LIST OF TABLES.................................. v111

1. INIRODUCTION....................................... 1

1.1 Background.................................... 1

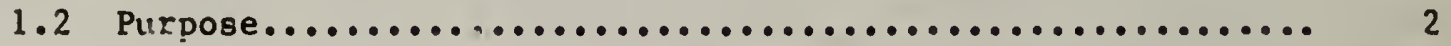

2. FIRE ZONE SAFETY IN HEALTH CARE FACILITIES................ 3

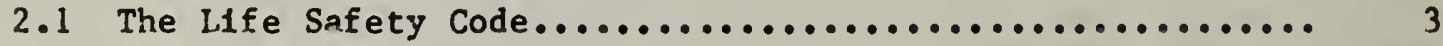

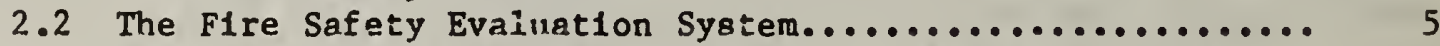

2.3 The Prescriptive Requirements of the iffe Safety Code..... 12

3. THE FIRE SAFETY EVALUATION SYSTEM COST MINIMIZER

(FSESCM) COMPUTER PROGRAM.......................... 16

3.1 Criter1a Used in Designing the ESESCM Computer Program.... 16

3.2 The Progiam Output and Its Interpretation.............. 31

3.3 A Case Study.................................. 35

4. CONCLUDING REMARKS............................... 55

REFERENCES....................................... 57 
2.1 Sample Worksheet: Methodology for Calculating Occupancy

Risk Factor........................................ 8

2.2 Sample Worksheet: Values of Safety Parameters as a

Function of the Level of Safety Provided.

2.3 Sample Worksheet: Methodology for Evaluating the Level of Containment Safety, Extinguishment Safety, People Movement Safety, and General Safety Provided Within the Fire Zone.......... 10

2.4 Sample Worksheet: Methodology for Determining if the Level of Safety Provided Within the Fire Zone is Equivalent to that Required by the Life Safety Code............. 11

3.1 FSESCM Cost Estimation Worksheet......................... 22

3.2 Sample Output Summarizing the Data Input for a Typical F1re Zone.......................................... 38

3.3 Sample Output Summarizing the Estimated Cost for Each Potential Retrofit for a Typical Fire Zone................... 40

3.4 Sample Output Showing the Solutions Generated for a Typical Fire Zone.....................................42

3.5 Sample Output Showing the Best Combination of Design Equivalent Solutions.................................. 44

3.6 Sample Output Showing Design Equivalent Solutions Based on Smoke Detection and Alarm in Corridors and Habitable Spaces.............................................46

3.7 Sample Output Showing Design Equivalent Solutions Based on Smoke Detection and Alarm in the Total Space.................. 48

3.8 Sample Output Showing Design Equivalent Solutions Based on No Dead Ends in Corridors............................. 50

3.9 Sample Output Showing the Detalls of the Prescriptive Compliance Solution. 


\section{LIST OF FIGURES}

3.1 Flowchart of the FSESCM Computer Program................ 18

3.2 Outputs of the FSESCM Computer Program................... 33

3.3 Layout of the Patient Room Floors for the Case Study Bullding......................................... 36

3.4 Alternative Retrofit Packages for the Case Study Bullding............................................ 54

\section{LIST OF TABLES}

2.1 Values of Safety Parameters Corresponding to Prescriptive Compliance to the Life Safety Code for Hospitals......................................... 13

2.2 Values of Safety Parameters Corresponding to Prescriptive Compliance to the Life Safety Code for Nursing Homes........................................ 14

3.1 Input Data Requirements for the FSESCM Computer Program....................................... 20

3.2 User Options Avallable with the FSESCM Computer Program......................................... 21

3.3 Retrofit Measures Considered by the FSESCM Computer Program....................................... 27

3.4 Design Varlable Qualifiers Used In Establishing the 40 Design Classifications.............................. 34 


\subsection{BACKGROUND}

The identification of cost-effective levels of fire safety in health care facilities is a major concern to hospital administrators, fire safety engineers, and public policy makers. Rising construction and operating costs coupled with more stringent building codes and continuing advances in medical and building technology have complicated the issue, forcing health care facility administrators to assess carefully the alternative means through which they can design, construct, or update their facilities. Although multiple death fires in health care facilities are rare occurrences, the potential for major losses of life and property does exist and should be recognized in the selection of fire safety measures. This potential and its implied need for a national commitment to fire safety in health care facilities has been emphasized in numerous congressional hearings.

The National Fire Protection Association (NFPA) has long been recognized as a vehicle through which such a national commitment could be achieved. For over 60 years the NFPA has been a leader in the development of voluntary codes which establish acceptable fire safety levels. The Life Safety Code is currently a widely used guide for providing fire safety in buildings. Although the code may be thought of as a prescriptive, since it defines only a limited number of options as admissible solutions for life safety in designated occupancies, the performance concept can be explicitly introduced through a provision which allows for equivalent solutions. 2

In light of this provision, the National Bureau of Standards' Center for Fire Research through support from the Department of Health and Human Services has developed a system for determining how combinations of several widely accepted fire safety systems could be used to provide a level of safety equivalent to that required by the Life Safety Code. 3 The equivalency methodology which emerged from this effort is particularly attractive since it lends itself to mathematical optimization techniques. The precision gained through the use of mathematical optimization techniques should result in improved fire safety in health care facilities due to its potential for resolving many of the differences of opinion surrounding the cost impacts of fire safety in health care facilities in general and the Life Safety Code in particular.

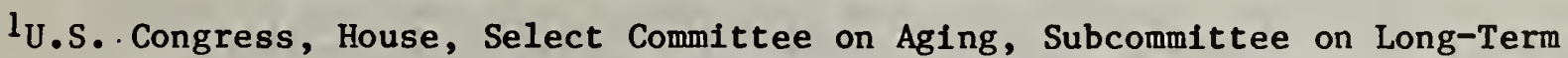
Care, Tragedy of Multiple Death Nursing Home Fires: The Need for a National Commitment to Safety, September 1976 .

2National Fire Protection Association, Code for Safety to Life from Fire in Buildings and Structures, NFPA 101-1981, Quincy, Mass., 1981.

${ }^{3}$ H. E. Nelson and A. J. Shibe, A System for Fire Safety Evaluation of Health Care Facilities, National Bureau of Standards, NBSIR 78-1555, Washington, D.C., 1980 . 


\subsection{PURPOSE}

The purpose of this report is to review the most important factors which led to the development of the Fire Safety Evaluation System Cost Minimizer (FSESCM) computer program which identifies the least-cost means for bringing a health care faclilty into compliance to the Life Safety Code. The FSESCM program 18 based on the FIre Safety Evaluation System developed by the Center for Fire Research; this system has been adopted into the Life Safety Code, NFPA 101,1 as an append $1 x^{2}$. Any solutions which the program produces can thus be proven equivalent to the code. Since each of the parameters used in the equivalency methodology has a unique value which corresponds to prescriptive compliance, it is also possible to quantify the cost savings attributable to the equivalency methodology over that of prescriptive compliance. Although the FSESCM program is useful for both new and existing facilities, 1 t is anticipated that its primary use wlll be identifying alternative courses of action open to decision makers faced with retrofltting existing facilities.

The computer program uses as its primary input information collected as an integral part of any thorough fire safety evaluation. Th1s information permits the current state of the health care facllity to be unamblguously Identified. The least-cost combination of retrofits is based on:

1. the current condition of the health care facllity;

2. the minimum passing "score" needed to achleve compliance, and

3. the anticipated costs of each retrofit measure.

The computer program then generates and analyzes a class of alternat1ve retrofits. The optimal combination of retrofits and any alternatives which the program produces, usually between 10 and 20 , are then summarized in tabular form and ranked according to cost.

TUnless stated otherwise, whenever the NFPA 101 document is referenced it w11 be assumed that the text refers to the 1981 edition of the code.

${ }^{2}$ Appendix C of NFPA 101 describes the Fire Safety Evaluation System for health care occupancies. For those readers wishing an extended discussion of this as well as other topics in NFPA 101, the Life Safety Code Handbook is highly recommended (c.f., James K. Lathrop, editor, Life Safety Code Handbook, National Fire Protection Association, Quincy, Mass., 1981). 


\subsection{THE LIFE SAFETY CODE}

The concept of fire safety has changed dramatically in recent years. This is due not only to more advanced and complicated technology, but also to changes in social structure. In the last 150 years, fire safety has taken on meaning beyond merely preventing major conflagrations through the use of public fire departments. Today the emphasis is on prevention through the development of product standards which significantly reduce the probability of ignition for objects such as upholstered furniture within the building. 1 Although the efficiency of public fire departments and the consideration of product standards are both of fundamental importance in any systematic treatment of the fire safety problem, careful consideration must also be given to the goal of limiting fires to the building of origin. Historically, this goal has been addressed through the use of bullding codes. This report focuses on that aspect of the fire safety problem. In particular, all analyses of the fire safety problem are in terms of the Life Safety Code. 2

Since its origin in 1913, the Life Safety Code has been constantly revised as more reliable technical and empirical evidence has become available. The National Fire Protection Association's early work on the Life Safety Code was concerned primarily with the identification and analysis of the causes of death in major fires. From these analyses came recommendations for fire drills, standards for construction of stairways and fire escapes, as well as guidelines on the placement of the means of egress.

Spectacular fires resulting in major losses of life and property and large numbers of injuries, led to the increased use of the NFPA document for legal regulatory purposes. Unfortunately, the numerous advisory provisions contained in the document necessitated that a major revamping of the document be performed in order to ensure that it was appropriate and adequate for legal use. The present Life Safety Code is aimed at addressing this need. It is revised periodically to reflect advances in fire and building technology. Prior to an examination of the equivalency methodology, however, it may be instructive to review several portions of the Life Safety Code. This review provides a framework which facilitates the derivation of the equivalency methodology from the code.

1J. W. Lyons, "Fire Research and Fire Safety: A Status Report on the Situation in the United States," in A. F. Robertson, ed. Fire Standards and Safety, American Society of Testing Materials, Special Technical Publication 614, Philadelphia, 1977.

2 The Life Safety Code was developed by the National Fire Protection Association. It is important to point out that the Life Safety Code is a voluntary code. Although the Life Safety Code is voluntary, it becomes mandatory when adopted as part of a building regulation. Health care facilities are also affected by other codes which may significantly affect the cost impacts of the Life Safety Code (c.f., Joseph G. Sprague, "Common Sense Approach Needed in Dealing with Safety," Hospitals, Vol. 51, February 1977, pp. 67-75). 
As mentioned in chapter 1, the Life Safety Code admits only a limited number of solutions to life safety in designated occupancies. In this report, particular emphasis w11 be placed on chapters 12 and 13 of NFPA 101 which are concerned with health care facllitles. (New health care facllities are treated in chapter 12; existing health care facllitles are treated in chapter 13.) The technical foundations for the requirements outlined in chapters 12 and 13 of NFPA 101 are concerned with three broad classes of fire safety. These classes are: (1) Means of Egress; (2) Features of F1re Protection; and (3) Bullding Service Equipment. A brief discussion of each class, including an enumeration of the Individual fire safety measures, w1l be used as background material for introducing the equivalency methodology. The first class, Means of Egress, is defined as follows:

"A continuous and unobstructed way of exit travel from any point in a bullding or structure to a public way. It consists of three separate and distinct parts: (a) the way of exit access, (b) the exit, and (c) the way of exit discharge".2

Means of Egress therefore 1nclude such 1tems as: doors, interior and exterior stairs, horizontal exits, ${ }^{3}$ ramps, exit passageways, escalators, fire escape stairs and ladders. The 1llumination and marking of means of egress is an explicit requirement within the code. The second class, Features of fire Protection, includes the protection of vertical openings, 4 interior finishes, protective signaling systems, automatic sprinklers and other extinguishment equipment, segregation and protection of hazards, smoke partitions and fire doors. The third class, Bullding Service Equipment, includes air conditioning, ventilation, heating, cooking, and incineration.

A careful examination of the preceding lists reveals that the level of protection provided by some of the fire safety measures in one class may affect the level of other fire safety measures. Consequently, the Life Safety Code contains a redundancy clause to insure that the fallure of a single protection device or method will not result in a major fallure of the entire system. lNFPA 101 defines an existing bulding as one already in existence when the
code went into effect.

2 Provision $5-1.2 .1$.

${ }^{3}$ NFPA 101 defines a horizontal exit as a way of passage from one bullding to an area of refuge in another bullding on approximately the same level, or a way of passage through or around a wall or partition to an area of refuge on approximately the same level in the same bullding, which affords safety from fire or smoke from the area of escape and areas communicating therewith.

${ }^{4} \mathrm{~A}$ vertical opening is an opening through a floor. 
The redundancy clause is thus of primary importance in any application of (or modification to) the Life Safety Code. Consequently, any alternative solutions to the level of safety mandated by the Life Safety Code, such as those provided by the Center for Fire Research's equivalency methodology, also must guarantee that the level of fire safety provided is not dependent upon any single fire safety measure.

\subsection{THE FIRE SAFETY EVALUATION SYSTEM}

The core concept in the equivalency methodology is its treatment of fire safety in an individual fire zone of a health care facllity. The term fire zone is defined as a space separated from all other spaces by floors, horlzontal exists, or smoke barriers. (Where a floor 18 not subdivided by horizontal exits or smoke barriers the entire floor is the zone.) Three basic classifications of fire safety are used in assessing the level of safety provided in a particular fire zone. 1 These three classifications are: (1) occupancy risk; (2) bullding safety features; and (3) safety redundancy.

The first two fire safety classifications contain a set of factors which are subdivided into a set of states. For each factor there is a descriptor which defines the state and a score, state value, which reflects the relative degree of risk or safety. Through a serles of manipulations involving various factor/state combinations, it is possible to determine the level of safety provided within a particular fire zone. Each of the three basic fire safety classifications will now be examined.

Occupancy Risk

Occupancy risk reflects the number of people affected by a given fire, the level of fire they are likely to encounter, and their ability to protect themselves. The occupancy risk for a particular fire zone is assessed by evaluating the level of safety for each of the following five factors:

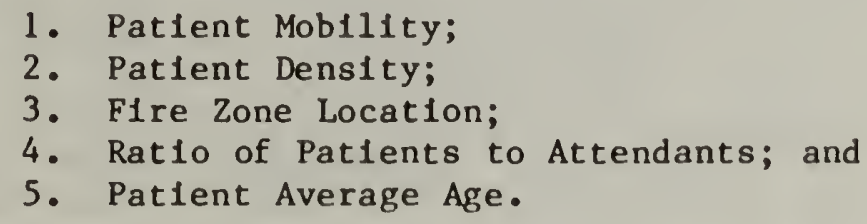

A state value, is obtained from a worksheet and recorded. When multiplied together, these values produce an occupancy risk factor. The occupancy risk factor is then adjusted to reflect whether the bullding is new or existing.

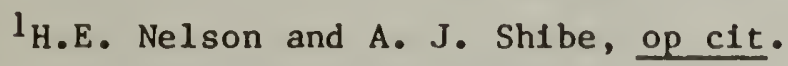




\section{Building Safety Features}

Building safety features reflect the ability of the bullding and its fire protection systems to provide measures of safety commensurate with the risk. The building safety features for the fire zone are assessed by evaluating the level of safety for each of the following 13 factors:

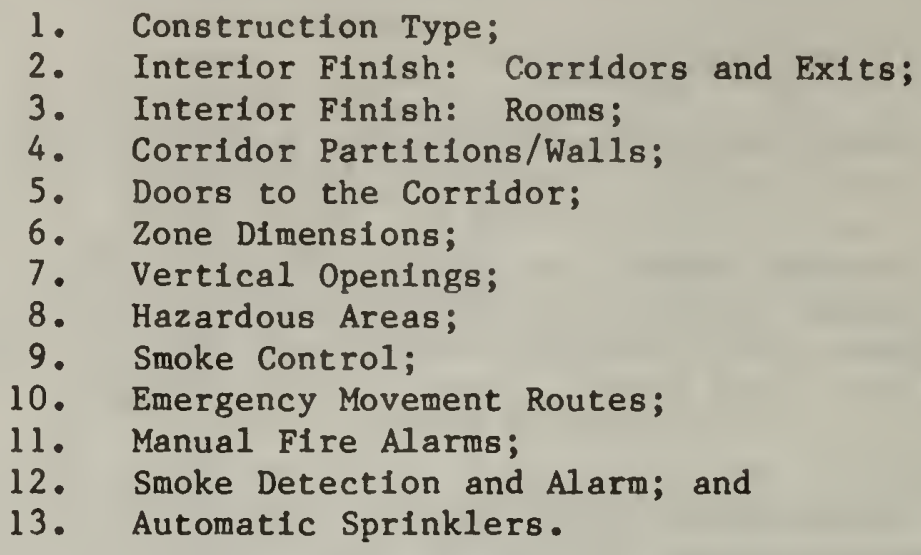

A state value corresponding to the level of safety associated with each building safety feature is then taken from a worksheet and recorded.

Safety Redundancy

It is important to point out that there is not an explicit statement of what constitutes the redundancy required by the Life Safety Code. Consequently, an important difference between the Fire Safety Evaluation System and the Life Safety Code is the way in which redundancy is determined. Since the Fire Safety Evaluation System is a quantitative system for evaluating fire safety, the redundancy requirement must be explicit. The integration of information on a set of factors which affect system performance with a set of safety categories involved extensive interaction among code officials, fire marshalls, fire scientists and representatives of the health care industry. The term redundancy as used in the remainder of the report will therefore refer to the explicit redundancy of the Fire Safety Evaluation System and not that implied by the Life Safety Code. The redundancy clause plays a crucial role in identifying acceptable levels of fire safety. This issue is addressed in the equivalency methodology through the use of a four-way safety redundancy. The four safety categories are:

1. Containment Safety;

2. Extinguishment Safety;

3. People Movement Safety; and

4. General Safety.

Safety redundance is evaluated by entering the appropriate state value for each of the 13 bullding safety features in the appropriate places on the worksheet. These values are then summed to get a safety score. (The worksheet is designed so that one score results for each of the four safety redundancy categories.) Each of these scores are then entered on the fourth and final page of the worksheet. 
Equivalency to the Life Safety Code may then be tested by entering the scores assoclated with the mandatory safety requirements for containment safety, extinguishment safety, people movement safety, and the occupancy risk factor In the space provided on the worksheet. If the differences in the two sets of scores are non-negative in all four cases, then the fire zone 18 deemed to be in compliance with the Life Safety Code. The safety redundancy clause of the Life Safety Code has as an Implication that the minimum level of safety be met or exceeded for each of the four safety categorles.

How the underlying concepts which went into the formulation of the equivalency methodology comes together in the Fire Zone Safety Evaluation Worksheet, 18 1llustrated in exhibits 2.1 through 2.4. It 1s important to point out that the tables shown in exhibits 2.1 through 2.4 may differ slightly from those presented in the report by Nelson and Shibe. The source of the differences relates to changes made by the NFPA committees charged with incorporating the F1re Safety Evaluation System into the Life Safety Code. Since appendix C of NFPA 101 is the official version of the Fire Safety Evaluation System for measuring equivalence to the 1981 edition of the Life Safety Code, It was decided to include these tables rather than those published in the report by Nelson and Shibe.

Exhibit 2.1 consists of Tables 1,2 and 3 of the Fire Zone Safety Evaluation Worksheet. These tables provide the means for calculating the occupancy risk factor. Table 1 of the worksheet provides the values for each risk parameter. Based on the guidelines given in appendix $C$ of NFPA 101, the appropriate value for each of the five risk parameters is then determined. The values Identified in Table 1 are then entered in the spaces coded $M, D, L, T$, and $A$ in Table 2. These values are multiplied together and entered in the space coded as F (see exhibit 2.1). The score recorded in box F is the "unadjusted" occupancy risk factor. The "unadjusted" occupancy risk factor calculated in Table 2 is then entered in efther Table 3A or 3B. In the event that the building was constructed after the 1981 Life Safety Code went into effect, Table 3A should be used. The occupancy risk factor is then defined as the product of the "unadjusted" occupancy risk factor and the Table $3 \mathrm{~A}$ weighting factor of 1.0. If the bullding was constructed before the 1981 Life Safety Code went into effect, Table 3B should be used. In this case, the occupancy risk factor is defined as the product of the "unadjusted" occupancy risk factor and the Table $3 B$ welghting factor of 0.6 .

Exhibit 2.2 consists of Table 4 of the Fire Zone Safety Evaluation Worksheet. Table 4 lists each of the 13 bullding safety features, defines the states within each one, and gives a state value for each level of fire safety. A brief description of the state within the system is also given in a small box immediately above each state value. For example, the states for interior finishes in corridors and exits have a value of -5 for class $C$ finishes, a value of 0 for class $B$ finishes, and a value of 3 for class $A$ finishes. In this case the descriptors are class $C$, class $B$, and class $A$, respectively. Specifications which enable the evaluator to determine the appropriate level to check for each building safety feature are given in appendix C of NFPA 101. In all cases, however, the state of the bullding safety feature is determined by a "worst case" condition within the fire zone. 
Exh1bit 2.1 Sample Worksheet: Methodology for Calcularing Occupancy Risk Pactor

\section{Table 1. OCCUPANCY RISK PARAMETER FACTORS}

\section{RISK PARAMETERS RISK FACTOR VALUES}

1. PATIENT

MOBILITY (M)

\begin{tabular}{|c|c|c|c|c|}
\hline $\begin{array}{c}\text { MOBILITY } \\
\text { STATUS }\end{array}$ & MOBILE & $\begin{array}{c}\text { LIMITED } \\
\text { MOBILITY }\end{array}$ & $\begin{array}{c}\text { NOT } \\
\text { MOBILE }\end{array}$ & $\begin{array}{c}\text { NOT } \\
\text { MOVABLE }\end{array}$ \\
\hline RISK FACTOR & 1.0 & 1.6 & 3.2 & 4.5 \\
\hline
\end{tabular}

2. PATIENT

DENSITY (D)

\begin{tabular}{|c|c|c|c|c|}
\hline PATIENT & 1.5 & 6.10 & 11.30 & $>30$ \\
\hline RISK FACTOR & 1.0 & 1.2 & 1.5 & 2.0 \\
\hline
\end{tabular}

3. ZONE

LOCATION (L)

\begin{tabular}{|c|c|c|c|c|c|}
\hline FLOOR & $1 S T$ & $\begin{array}{c}2 \mathrm{ND} O \mathrm{OR} \\
3 \mathrm{RD}\end{array}$ & $\begin{array}{c}\text { 4TH TO } \\
6 \mathrm{TH}\end{array}$ & $\begin{array}{c}7 \mathrm{TH} \text { AND } \\
\text { ABOVE }\end{array}$ & $\begin{array}{c}\text { BASE- } \\
\text { MENTS }\end{array}$ \\
\hline RISK FACTOR & 1.1 & 1.2 & 1.4 & 1.6 & 1.6 \\
\hline
\end{tabular}

4. RATIO OF

PATIENTS TO

ATTENDANTS (T)

\begin{tabular}{|c|c|c|c|c|c|}
\hline $\begin{array}{c}\text { PATIENTS } \\
\text { ATTENDANT }\end{array}$ & $\frac{1.2}{1}$ & $\frac{3.5}{1}$ & $\frac{6.10}{1}$ & $\frac{>11}{1}$ & $\begin{array}{c}\text { OME OR* } \\
\frac{\text { MORE }}{\text { NOME }}\end{array}$ \\
\hline RISK FACTOR & 1.0 & 1.1 & 1.2 & 1.5 & 4.0 \\
\hline
\end{tabular}

5. PATIENT

AVERAGE

AGE (A)

\begin{tabular}{|c|c|c|}
\hline AGE & $\begin{array}{c}\text { UNDER 65 YEARS } \\
\text { AND OVER IYEAR }\end{array}$ & $\begin{array}{l}65 \text { YEARS \& OVER } \\
\text { I YEAR \& YOUNGER }\end{array}$ \\
\hline RISK FACTOR & 1.0 & 1.2 \\
\hline
\end{tabular}

* RISK FACTOR OF 4.0 IS CHARGED TO ANY ZONE THAT HOUSES PATIENTS WITHOUT ANY STAFF IN IMMEDIATE ATTENDANCE

Table 2. OCCUPANCY RISK FACTOR CALCULATION

OCCUPANCY RISK $\stackrel{M}{\square} \times \stackrel{D}{\square} \times \stackrel{L}{\square} \times \stackrel{\mathrm{T}}{\square} \times \stackrel{A}{\square}=\stackrel{\mathrm{F}}{\square}$

Table 3A. (NEW BUILDINGS)

$1.0 \times \square=\stackrel{F}{\square}$

Table 3B. (EXISTIKG BUILDINGS)

$0.6^{\times}{ }^{\mathrm{F}}=\stackrel{\mathrm{R}}{\square}$


Exh1b1t 2.2 Sample Worksheet: Values of Safety Parameters as a Funct1or. of the Level of Safety Provided

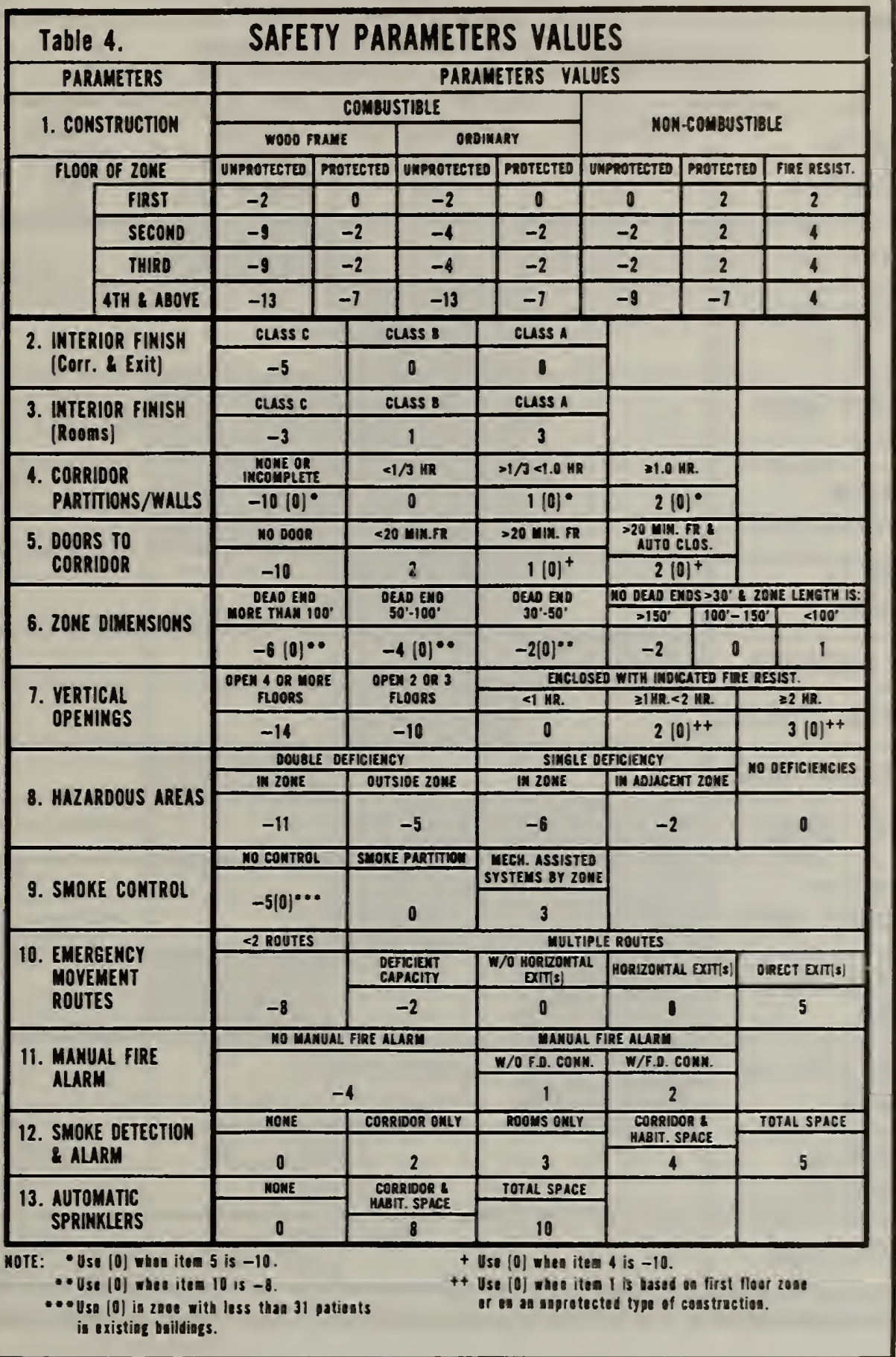


Exh1b1t 2.3 Sample Worksheet: Methodology for Evaluating the Level of Contalnment Safety, Ext1ngulshment Safety, People Movement Safety, and General Safety Provided Within the F1re Zone

\section{Table 5. INDIVIDUAL SAFETY EVALUATIONS}

\begin{tabular}{|c|c|c|c|c|}
\hline $\begin{array}{l}\text { SAFETY } \\
\text { PARAMETERS }\end{array}$ & $\begin{array}{l}\text { CONTAINMENT } \\
\text { SAFETY } \\
\text { (S1) }\end{array}$ & $\begin{array}{c}\text { EXTINGUISHMENT } \\
\text { SAFETY } \\
\left|S_{2}\right|\end{array}$ & $\begin{array}{l}\text { PEOPLE } \\
\text { MOVEMENT } \\
\text { SAFETY }\left(S_{3}\right)\end{array}$ & $\begin{array}{l}\text { GENERAL } \\
\text { SAFETY } \\
\text { (SG) }\end{array}$ \\
\hline 1. CONSTRUCTION & & & & \\
\hline $\begin{array}{l}\text { 2. INTERIOR FINISH } \\
\text { (Corr. \& Exit) }\end{array}$ & & & & \\
\hline $\begin{array}{l}\text { 3. INTERIOR FINISH } \\
\text { (Rooms) }\end{array}$ & & & & \\
\hline $\begin{array}{l}\text { 4. CORRIDOR } \\
\text { PARTITIONS/WALLS }\end{array}$ & & & & \\
\hline $\begin{array}{l}\text { 5. DOORS TO } \\
\text { CORRIDOR }\end{array}$ & & & & \\
\hline 6. ZONE DIMENSIONS & & & & \\
\hline 7. VERTICAL OPENING & & & & \\
\hline 8. HAZARDOUS AREA & & & & \\
\hline 9. SMOKE CONTROL & & & & \\
\hline $\begin{array}{l}\text { 10. EMERGENCY } \\
\text { MOVEMENT ROUTE }\end{array}$ & & & & \\
\hline $\begin{array}{l}\text { 11. MANUAL FIRE } \\
\text { ALARM }\end{array}$ & & & & \\
\hline $\begin{array}{l}\text { 12. SMOKE DETECTION } \\
\text { \& ALARM }\end{array}$ & & & & \\
\hline $\begin{array}{l}\text { 13. AUTOMATIC } \\
\text { SPRINKLERS }\end{array}$ & & & $\div 2=$ & \\
\hline TOTAL VALUE & $s_{1}=$ & $s_{2}=$ & $S_{3}=$ & $S_{G}=$ \\
\hline
\end{tabular}


Exhibit 2.4 Sample Worksheet: Methodology for Determining if the Level of Safety Provided Within the Fire Zone 18 Equivalent to That Required by the Life Safety Code

\begin{tabular}{|c|c|c|c|c|c|c|}
\hline \multirow[b]{2}{*}{ ZONE LOCATION } & \multicolumn{2}{|c|}{$\begin{array}{c}\text { CONTAINMENT } \\
\mathrm{S}_{\mathrm{a}}\end{array}$} & \multicolumn{2}{|c|}{$\begin{array}{c}\text { EXTINGUISHMENT } \\
\text { Sb }\end{array}$} & \multicolumn{2}{|c|}{$\begin{array}{c}\text { PEOPLE MOVEMENT } \\
\text { SC }\end{array}$} \\
\hline & New & Exist. & New & Exist. & New & Exist. \\
\hline FLOOR 1 & 9 & 5 & $6(4)^{*}$ & 4 & $6(4)^{*}$ & 1 \\
\hline ABOVE OR BELOWFLOR 1 & 14 & 9 & $8(6)^{*}$ & 6 & $9(7)^{*}$ & 3 \\
\hline
\end{tabular}

* Use values in parentheses ( ) for hospitals

\begin{tabular}{|c|c|c|c|c|c|c|}
\hline \multicolumn{5}{|c|}{ ZONE SAFETY EQUIYALENCY EVALUATION } & YES & NO \\
\hline $\begin{array}{l}\text { CONTAINMENT } \\
\text { SAFETY }\left(S_{1}\right)\end{array}$ & less & $\begin{array}{l}\text { MANDATORY } \\
\text { CONTAINMENT }\left(S_{a}\right)\end{array}$ & $\geq 0$ & $=$ & & \\
\hline $\begin{array}{l}\text { EXTINGUISHMENT } \\
\text { SAFETY }\left[S_{2}\right]\end{array}$ & less & $\begin{array}{l}\text { MANDATORY } \\
\text { EXTINGUISHMENT }\left(S_{b}\right)\end{array}$ & $\geq 0$ & $S_{2}$ & & \\
\hline $\begin{array}{l}\text { PEOPLE } \\
\text { MOVEMENT } \\
\text { SAFETY }\left(S_{3}\right)\end{array}$ & less & $\begin{array}{l}\text { MANDATORY } \\
\text { PEOPLE } \\
\text { MOVEMENT } \quad\left|S_{c}\right|\end{array}$ & $\geq 0$ & $\overline{S_{3}}$ & & \\
\hline $\begin{array}{l}\text { GENERAL } \\
\text { SAFETY } \quad\left(S_{G}\right)\end{array}$ & less & $\begin{array}{l}\text { OCCUPANCY } \\
\text { RISK (R) }\end{array}$ & & $\square^{S_{6}}-\square^{\mathrm{R}}=$ & & \\
\hline
\end{tabular}


Exhibit 2.3 consists of Table 5 of the F1re Zone Safety Evaluation Worksheet. Table 5 provides the means for calculating the scores associated with containment safety, extinguishment safety, people movement safety, and general safety. These scores are then compared to the scores required by the Life Safety Code. The calculation 18 accomplished by entering the appropriate state value for each bullding safety feature in the light blocks of each row of the table. No values are entered in the shaded blocks. Each of the four columns is then summed to get the score for containment, extinguishment, people movement, and general safety. These scores are labeled $\mathrm{S}_{1}, \mathrm{~S}_{2}, \mathrm{~S}_{3}$, and $\mathrm{S}_{\mathrm{G}}$ respectively, in Table 5 .

Exhibit 2.4 contains Tables 6 and 7 of the Fire Zone Safety Evaluation Worksheet. These tables provide the means for determining if the fire zone possesses a level of fire safety equivalent to that of the 1981 Life Safety Code. Basically, this is done by taking the four scores calculated in containment safety, extinguishment safety, and people movement safety for the appropriate bullding type and fire zone location. These values are entered in the boxes labeled $\mathrm{S}_{\mathrm{a}}, \mathrm{S}_{\mathrm{b}}$, and $\mathrm{S}_{\mathrm{c}}$ in Table 7. The occupancy risk factor calculated on the first worksheet is then entered in the box labeled R. Based on these two sets of numbers it 18 possible to test if the fire zone possesses a level of safety equivalent to the Life Safety Code. This test 18 performed by determining if the differences between the first set of numbers $S_{1}, S_{2}, S_{3}$, and $S_{G}$ and the second set of numbers $S_{a}, S_{b}, S_{c}$, and $R$, in Table 7 are greater than or equal to zero.

\subsection{THE PRESCRIPTIVE REQUIREMENTS OF THE LIFE SAFETY CODE}

It was stated earlier that the Fire Safety Evaluation System contains a unique value for each bullding safety feature which corresponds to prescriptive compliance to the Life Safety Code. Tables 2.1 and 2.2 show the level of each bullding safety feature which corresponds to prescriptive compliance for hospitals and nursing homes, respectively. Each table is divided into a part for new bulldings and a part for existing bulldings; four cases are presented for each type of building.

For example, the first column of table 2.1 shows how to determine the value (and level) of each bullding safety feature which corresponds to prescriptive compliance for a new one-story hospital. In order to be in prescriptive conformance with the Life Safety Code for such a hospital, all framing and construction materials must be protected non-combustible type. Similarly, flame spread ratings for interior finishes are class A for corridors and exits and class B for rooms. Corridor partition walls should have a fire rating of at least 1 hour and all doors to the corridor should have a fire rating of at least 20 minutes. The corridors in the fire zone must not exceed 150 feet in length and have no dead ends greater than 30 feet in length. (No fixed solutions for vertical openings are applicable for single-story health care facilities.) Continuing down the first column shows that no deficlencles are permitted for hazardous areas; smoke partitions are required within the fire zone to insure an adequate level of smoke control; and the fire zone must have multiple emergency movement routes. The last three rows of the first column indicate that manual fire alarms with a fire department connection are required, and that no smoke detection and alarm devices or automatic sprinklers are required. 
Table 2.1 Values of Safety Parameters Corresponding to Prescriptive Compliance to the Life Safety Code for Hospitals

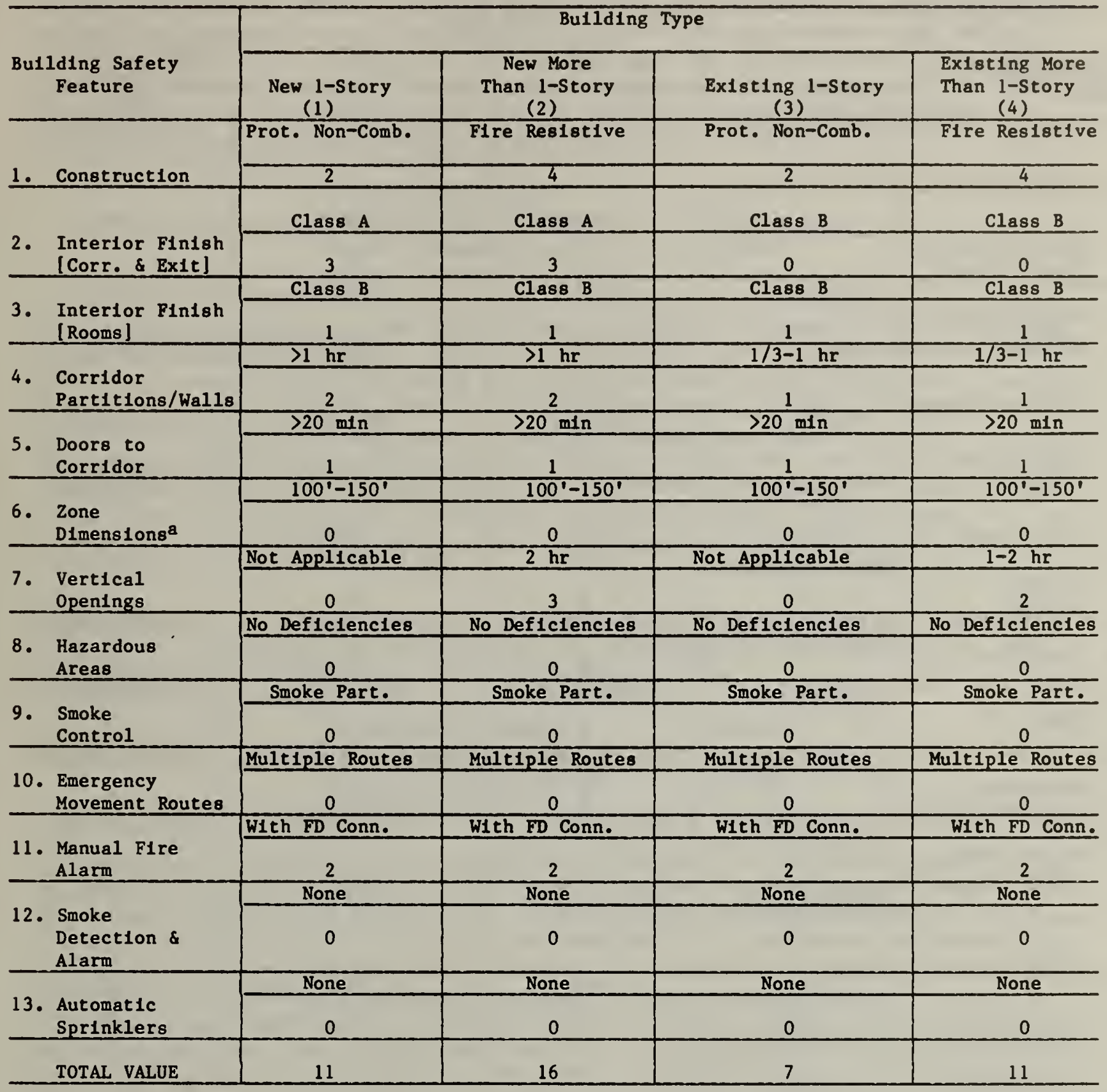

${ }^{a}$ No dead ends greater than 30 feet and corridor length is as recorded. 
Table 2.2 Values of Safety Parameters Corresponding to Prescriptive Compliance to the Life Safety Code for Nuring Homes

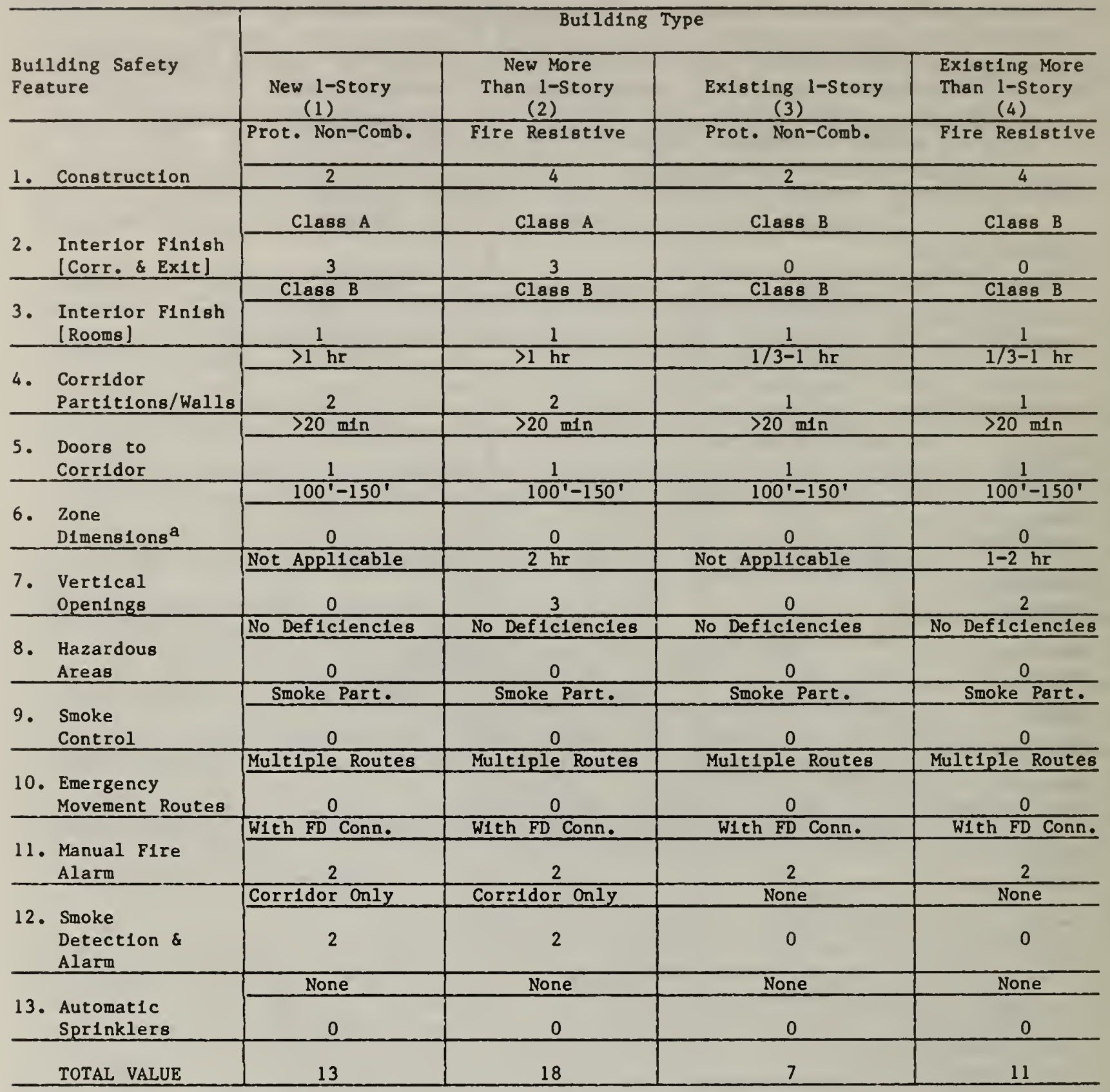

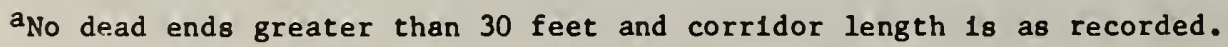


If the scores corresponding to the mandatory level of safety for each building safety feature are summed, a total score of 11 points results. Note that the column sum corresponds to the score for general safety (column 4 of Table 5 in the Fire Zone Safety Evaluation Worksheet). If the appropriate values from the first column in table 2.1 are now entered onto Table 5 of the Fire Zone Safety Evaluation Worksheet (see exhibit 2.3) one would find that the following score for each safety category results:

$\begin{array}{lr}\text { Containment Safety } & 9 \text { points } \\ \text { Extinguishment Safety } & 4 \text { points } \\ \text { People movement Safety } & 4 \text { points } \\ \text { General Safety } & 11 \text { points }\end{array}$

Note that the scores for the first three categories correspond to the values given as mandatory safety requirements for a fire zone located on the first floor of a new hospital in Table 6 of the Fire Zone Safety Evaluation Worksheet (see exhibit 2.4 in the previous section). Recall that the level of safety associated with the general safety requirement was calculated separately using Tables 1 through 3 on the first page of the Fire Zone Safety Evaluation Worksheet. In some cases the score requirement would exceed that resulting from prescriptive compliance to the Life Safety Code; thus, the score calculated from Tables 1 through 3 of the worksheet should be used.

Referring now to the second column of table 2.1, new hospitals with more than one-story, and performing the same set of calculations, one would find that the following score for each safety category results:

$\begin{array}{lrl}\text { Containment Safety } & 14 & \text { points } \\ \text { Extinguishment Safety } & 6 & \text { points } \\ \text { People movement Safety } & 7 \text { points } \\ \text { General Safety } & 16 \text { points }\end{array}$

In this case the first three categories correspond to the values given in the mandatory safety requirements (see Table 6 of the Fire Zone Safety Evaluation Worksheet presented in exhibit 2.4 of the previous section) for fire zones located above the first floor in a new hosiptal. If this exercise were repeated for the third and fourth columns of table 2.1 , it would be possible to derive the mandatory safety requirement values for fire zones located on the first floor and above the first floor in existing hospitals. Table 2.2 contains the same type of information but for nursing homes. Note that all new nursing homes must have smoke detection and alarm devices in all corridors in order to be in prescriptive compliance to the Life Safety Code. This accounts for the two point difference between hospitals and nursing homes regarding the extinguishment and people movement safety requirements. Thus, three of the four sets of mandatory safety requirement scores (containment safety, extinguishment safety, and people movement safety) can be derived from the four cases presented in tables 2.1 and 2.2. As mentioned earlier, the general safety requirements calculated in Tables 1 through 3 (see exhibit 2.1) can exceed the column sum from either table 2.1 or 2.2 . The occupancy risk calculation should therefore be used as the mandatory safety requirement for general safety. 


\subsection{CRITERIA USED IN DESIGNING THE FSESCM COMPUTER PROGRAM}

Past empirical work on fire safety in health care facllitles has shown that the use of the equivalency methodology could reduce the costs of compliance to the Life Safety Code by 30 to 50 percent. 1 Depending on the current condition of the health care facility, as measured by the state values in Table 4 of the Fire Zone Safety Evaluation Worksheet, the expected savings can exceed or fall below this range. Experts in the area of fire engineering claim that through the consideration of additional technical and engineering data these costs can be reduced even further. (Previous studies in other areas have demonstrated the cost saving potential of design innovations. ${ }^{2}$ ) Thus, the equivalency methodology not only permits substantial reductions in the costs of compliance to be achleved but also points to areas where additional engineering input would be most cost effective. This was an important issue in the design of the FSESCM program; it represents a significant improvement to the expected results presented in earlier studies. Although most of the uses of the equivalency methodology are geared toward existing bulldings, several major opportunities exist for its use in the design process. In particular, since its application is simple and straightforward, it is possible to assess numerous design alternatives quickly and efflciently. By the same token, questions concerning the fire zone's configuration, aesthetic qualities, level of fire safety, and costs can also be addressed.

Although all of the preceding toplcs are major factors in addressing the fire safety problem, perhaps the greatest advantage offered by the equivalency methodology is its amenability to mathematical optimlzation techniques. Since the formal mathematical optimization techniques can be easily programmed for use on computer systems, they provide a unique opportunity for systematically generating optimal compliance strategles for meeting the requirements of the Life Safety Code. In addition to the optimal or least-cost solution, optimization techniques provide an efficient and reliable procedure for generating alternative compliance strategles vis-a-vis the Life Safety Code.

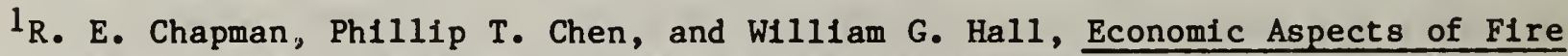
Safety in Health Care Facilities: Guidelines for Cost Effective Retrofits, National Bureau of Standards, NBSIR 79-1902, Washington, D. C., 1979. These studies were based on an earlier version of the Fire Safety Evalution System which used the 1973 edition of the Life Safety Code as its point of reference (National Fire Protection Assocition, Code for Safety to Life from Fire in Buildings and Structures, NFPA 101-1973, Quincy, Mass., 1974).

${ }^{2}$ Louls J. Kruger and Richard M. Patton, "More Fire Safety Can Cost Less," Hospitals, Vol. 51, February 1977, pp. 127-132. 
The FSESCM program addresses this issue directly by producing two groups of alternative solutions. The first group is based on the input condition of each fire zone. The objective here is to provide an opportunity to force each initial condition to stay in a solution and for each potential retrofit to be in a solution. (A potential retrofit is any state which has a higher score than the one input and which would be considered a viable candidate for upgrading for the facility under consideration.) The second group of solutions is based on a prespecified set of design variable qualifiers. The objective here is to insure design compatibility across fire zones. Both groups of solutions are generated for each fire zone input. The second group of solutions 18 used to produce a series of compliance strategies for the entire bullding within which the key design variable qualifiers are held constant. These solutions are then printed out in an ascending order of cost. The added information provided by the alternative solutions should assist health care facility administrators and construction specialists to assess better the costs of code compliance and hence resolve many of the differences of opinion surrounding the cost impacts of fire safety in general and the Life Safety Code in particular. In addition, the information conveyed by the alternative solutions provides an opportunity to introduce the impact that non-construction costs could have on the selection of the "best" retrofit strategy.

The FSESCM program discussed in this section is based on a mathematical technique known as linear programming. In 1 ts usual context linear programming deals with the problem of allocating limited resources among competing activities in an optimal way. At the foundation of any linear programming problem is a mathematical model which describes the problem of concern. In this case, the mathematical model is the Fire Safety Evaluation system. The term "Iinear" refers to the requirement that all mathematical functions in the model are linear. The term "program" 18 used in the general sense, since $1 t$ refers to a plan rather than a computer program per se. The basic reason why all mathematical functions involved in the problem are linear may be explained through reference to Table 4 and Table 5 of the Fire Zone Safety Evaluation Worksheet. In Table 4, there is one and only one level of each building safety feature possible at any one time. This is due to the requirement that the most hazardous level associated with each building safety feature determines its score. In Table 5, the score for each of the four safety redundancy requirements (containment safety, extinguishment safety, people movement safety, and general safety) is the sum of the values of the appropriate parameter identified in Table 4 as either the existing state or a potential retrofit. The linear programming procedure makes use of the entire Fire Safety Evaluation System; figure 3.1 displays the sequence of steps linking the Fire Safety Evaluation System to the FSESCM program. 


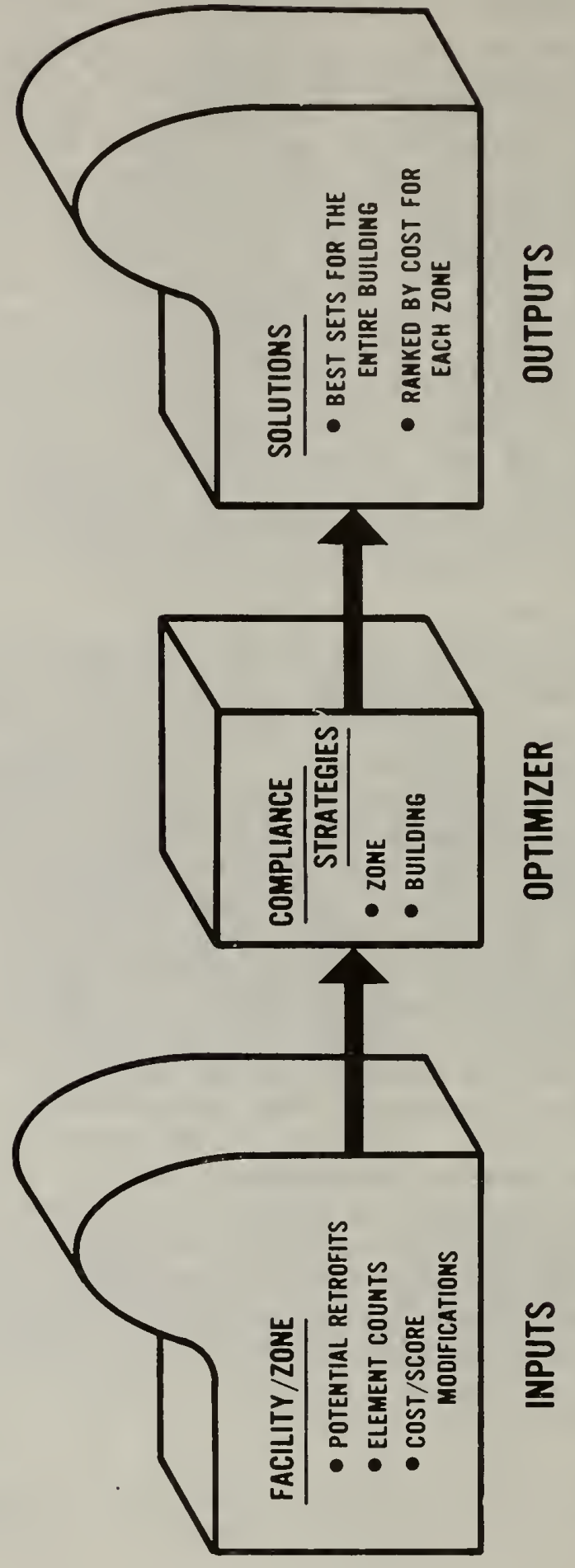


The information required to run the FSESCM program can be divided into two types. The first type is designated as "background information" (see table 3.1). This information covers such items as the name and location of the facility, who to contact if a question arises and the type of building being analyzed. The second type is designated as "specific information" and refers to data which must be input for each fire zone. These data are used to set up the optimization problem. They are summarized in table 3.1. The user also has available a set of options which affect the optimization problem in a variety of ways. Each option and its effect on the solution are described in table 3.2. All data are designed so that they can be easily and reliably collected at the same time as the fire zone is evaluated. As a first step the Fire Zone Safety Evaluation Worksheet must be used to identify the existing state of each of the 13 building safety features. Plugging this information into Table 5 of the worksheet permits the overall safety performance of the fire zone to be assessed. Using the information on the existing state for each feature as a starting point, engineering judgment may then be used to identify a set of potential retrofits. It is important to point out that based on engineering judgment some "theoretically" possible retrofits may be excluded. (A theoretically possible retrofit is any state which has a higher score than the existing state.) Once a set of potential retrofits has been identified, it is then necessary to count the number of elements which must be treated in order to move to a higher state. The elements are designed to capture all possible state transitions within Table 4 of the Fire Zone Safety Evaluation Worksheet. Since some of the states within Table 4 are not associated with a single element, a worksheet was developed which lists those building components requiring treatment in order to move from one state within a building safety feature to another. The information collected on the worksheet closely follows the design of Table 4 of the Fire Zone Safety Evauation Worksheet. The location of the fire zone(s) is first recorded. (It is important to point out that an allowance for grouping more than one fire zone has been made in the design of the worksheet.) Each of the 13 building safety features are than listed individually. To the right of the building safety feature name is a space for the current state number. The appropriate value is obtained by referring to the row of Table 4 of the Fire Zone Safety Evaluation Worksheet which corresponds to the building safety feature and counting rightward from the lowest state. For example, class A flame spread ratings on interior finishes in the corridors and exists is the third state within that building safety feature. Each of the critical elements are listed beneath the name of the building safety feature. In all cases the units (e.g., linear feet, square feet, etc.) are explicitly spelled out. Every effort was made to request only information which was readily available (e.g., by counting or taking off an existing set of floor plans) and could be easily verified if questions arose. The worksheet is shown as exhibit 3.1. The retrofit measures which the data from the worksheet permit the program to consider are summarized in table 3.3. Associated with each potential retrofit is a set of information on the one or more elements which must be treated to move to a higher state. For example, the number of "No Door" charges within the fire zone that would have to be removed in order to ensure that all doors had a fire rating of 20 minutes. All of this information is then stored in an "element count matrix." The product of the element count matrix and the element cost matrix, which is an integral part of the FSESCM program, yields the total cost associated with each potential retrofit. In order to address a variety of "what if" questions, the user has the option to modify the costs of a particular retrofit, the score required to pass, or both. 


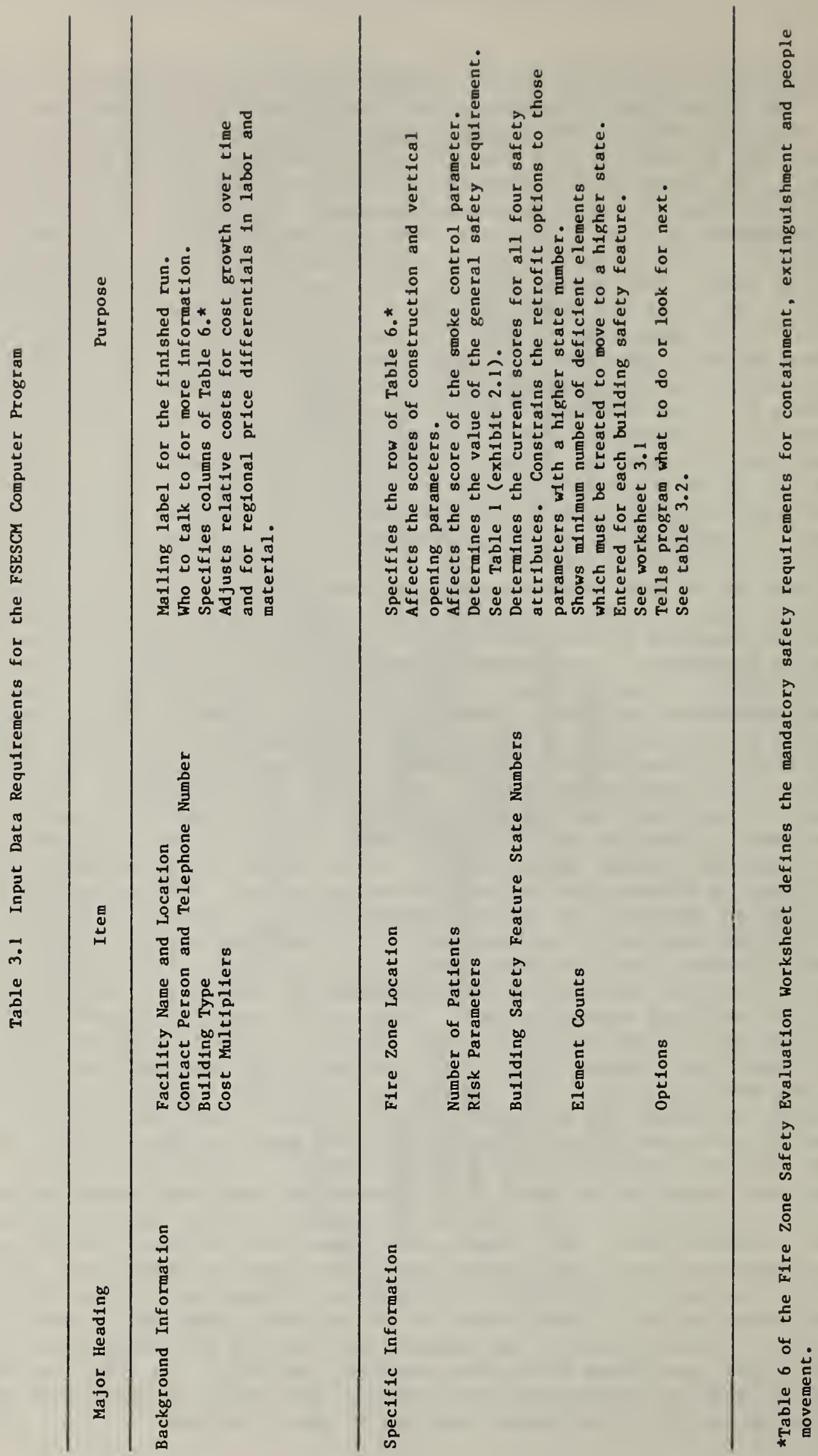


Table 3.2 User Options Available with the FSESCM Computer Program

Option Purpose

SOLVE

Causes an optimum solution for the fire zone

input to be generated. A set of retrofit

strategles which satisfy all of the requirements

of the Life Safety Code as well as several

bullding design criterla is also generated.

CHANGE

Adjusts the state transition cost to the value specifled by the user.

REQUIR

Increases a safety requirement by a percentage spectfled by the user.

NEXT

Tells the program to look for data on the next fire zone or the next bullding.

LAST

Signals that all data for the bullding under study have been analyzed and that the solutions for the total bullding should be output.

TEST

Checks al1 input data for consistency.

FINAL

Tells the program to stop; all data for the run have been output. 


\section{Exh1b1t 3.1 FSESCM Cost Estimation Worksheet}

For Zone( 8 ) Floor ( 8 )

\section{CONSTRUCTION} current state number.

If current condition of the fire zone 18 due to the fallure of certain walls, beams, or columns to meet the minimum f1re resistance ratings:

A. Estimate the area of bearing walls and partitions which could be re-sheathed to meet the requirements: square feet.

B. Estimate the length of columns and of beams needing protection: 11near feet of columns. linear feet of beams.

C. Est1mate the area of decking needing protection: square feet.

2. INTERIOR FINISH (CORRIDORS AND EXITS) current state number.

Estimate the total area which would need to be refinished to meet a h1gher rating:

A. Cellings :

1) Area of class C finish: square feet.

2) Area of class B finfsh: square feet.

B. Walls:

1) Area of class C finish: square feet.

2) Area of class B finfsh: square feet.

C. Carpeting:

Area of existing carpet: square feet.*

*Class I requirement applies only to new fac1litles and newly installed carpet in existing fac1lities. 
3. INTERIOR FINISH (ROOMS) current state number.

Estimate the total area which would need to be refinished to meet a higher rating:

A. Cellings:

1) Area of class C finish: square feet.

2) Area of class B finish: square feet.

B. Walls:

1) Area of class C finish: square feet.

2) Area of class B finish: square feet.

4. CORRIDOR PARTITIONS/WALLS current state number.

A. Estimate length of partition needed where none now exists: 11near feet.

B. Estimate length of partition which is incomplete from celling to slab: Iinear feet.

C. Estimate length of partitions currently rated:

Less than $1 / 3-\mathrm{HR}$ :

1/3-HR to 1-HR: linear feet. linear feet.

D. Number and area of see-through panels with ordinary glass:

1) Use existing frame: Number

2) Requires new frame: Number , area In square Inches , area in square inches

5. DOORS TO CORRIDOR current state number.

A. Number of doorways without doors: single; double.

B. Number of doorways where both door and frame are deficient (e.g., hollow wood door in wood frame):

single; double. 


\section{Exhibit 3.1 (continued)}

C. Number of doorways where door only 18 deficient (e.g., hollow wood door in steel frame):

$$
\text { single; __ double. }
$$

D. Number of doors without closers which can normally stand closed (e.g., lounges, offices, ut1lity spaces, etc.):

E. Number of doors whthout closers wh1ch must normally stand open (e.g., patient rooms):

F. Number of doors w1th broken or no latch:

G. Number of doors whth ordinary glass view panel:

6. ZONE DIMENSIONS current state number.

A. If long dead ends, can a cross connection be made to a parallel corr1dor?

If yes, I1near feet of connection.

B. If no, number of stalrways needed to reduce dead ends to:
Less than 30 feet:
Less than 50 feet: inter1or interior
Less than 100 feet: 1nterior Eloors;
floor $;$
floors exterior exterior exterior floors. floors. floors.

C. If a new smoke partition was installed to reduce zone dimensions:

a. Can existing walls be used from outside walls to the new corridor partition?

b. If no, give linear feet of new partition required: linear feet slab to slab; linear feet celling to slab.

c. Number of duct penetrations whthout smoke dampers:

7. VERTICAL OPENINGS current state number.

A. Number of doors needed where existing enclosure is otherwise acceptable: doors and Frames; doors only.

B. Estimated area to be sheathed where existing framing is acceptable: floors; square feet per floor; doors per floor.

C. Estimated area to be framed and sheathed: floors; square feet per floor; doors per floor. 
Exhibit 3.1 (continued)

8. HAZARDOUS AREAS

current state number.

List floor area and current information for each:

Area

Score Sprinklered?

Enclosure? Doors? Special $<1-H R \quad \geqslant 1-H R \quad\langle B \quad>B \quad$ Notes

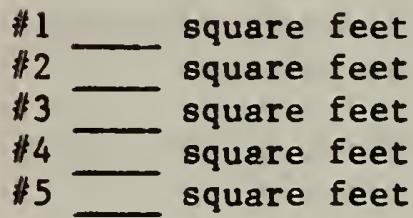

9. SMOKE CONTROL current state number.

A. Number of floors without smoke partitions:

NOTE: Mechancially assisted systems require individual design and cost estimation.

10. EMERGENCY MOVEMENT ROUTES current state number.

A. If a new horizontal exit was installed:

a. Can existing partitions be used from outside walls to the partition? NOTE: Horizontal exits must be continuous to the ground.

b. If no, give linear feet of new 2-HR partition required: slab to slab; ceiling to slab.

c. Number of duct penetrations without fire dampers

B. Number of deficient exits:

Reason for deficiency: Insufficient enclosure fire resistance; inadequate dimensions.

C. Number of emergency lights needed:

11. MANUAL FIRE ALARM current state number.

Is there currently a fire alarm system which could be expanded? yes; no.

A. Number of pull stations needed to have one at every exit and nursing station:

B. Fire department connection currently provided? yes; no. 
Exh1b1t 3.1 (cont1aued)

12. SMOKE DETECIIOII AMD ALAPM current state number.

A. Length of cortldors not now protected: lizear feet.

3. liuber of pat1ent rooms not now protected:

C. Iotal floor area of all spaces over 600 square feet not now protected: sçuare feet.

D. liveber of son-pat1ent roons not now protected:

2. Iruzber of bathroo=s and closets:

13. ALIOMAIC SPIIRLERS current state number.

A. Type of system desired:

(1) (vet, exposed);

(3) $\longrightarrow$ (dry, exposed);

(2) (wet, concealed);

(4) (dry, concealed).

3. Has the existing water supply been deterained to be adequate for spriakler systens?

(1)__ adequate; (2) not adequate;

(3) not deteralned.

C. Length of corridors not nor protected: l1near feet.

D. Inuber of roous not now protected:

$<200$ scuare feet 400-600 square feet ; 200-400 square feet

2. Total floor area of all spaces (1ncluding any wards) over 600 square feEt not nor protected: squiars feet.

P. Total floor area of bullding (zone): square feet.

G. linmber of bathrooms and closets: 
Table 3.3 Retrofit Measures Considered by the FSESCM Computer Frogran

Bullding Safety Feature ketrofit

1. Construction

2. Interior Finish

(Corridors and Exits)

3. Interior Flnish (Rooms)

4. Corridor Partitions/Walls

5. Doors to Corridor

6. Zone Dimensions

7. Vertical openings

8. Hazardous Areas

9. Smoke Control

10. Emergency Movement Routes

11. Manual fire Alarm

12. Smoke Detection and Alarm

13. Automatic Sprinklers

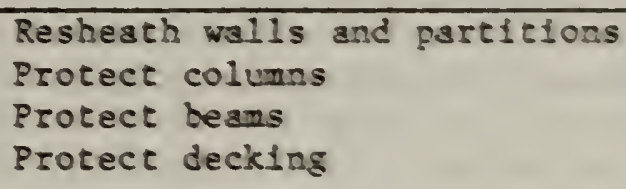

Resheath walls and gartitfors

Protect colums

Protect beans

Protect decking

Cost walls with retardant

Coat cellings with retardant

Install earpet

Cost walls with retsrdsnt

Cost cellings with retardsat

Install partition slab to slab

Extend existing partitions to slab

Replace see-through panels and frames

Replace see-through panels only

Install drywall

Replace doors snd frames

Replace doors only

Replace latch

Replace view panel

Install closers

Install cross connection

Install stsitway

Install smoke partition

Frame and sheath

Sheath only

Install doors and frsmes

Install doors only

Install sprinklers

Install Class $B$ door

Install drywall

Install smoke partition

Insta11 emergency lighting

Install horfzontsl exit

Insta11 pull station

Connect to fire depsrtment

Install fonjation detectors

Install wet system

Install dry system 
The Information identifled in the sequence of steps outlined above is all that is required to exercise the FSESCM program. The FSESCM program 1s written in FORTRAN, a widely-used language for sclentific and technical applications, and complies with the specifications for the full FORTRAN 77 language defined in the $\mathrm{X} 3.9$ ANSI standard.1,2 (It is not necessary for the user to understand FORTRAN in order to exercise the program.) The model is designed to be run on any system which: (1) complles with the X3.9 ANSI standard; and (2) can accomodate intermediate sized programs. Compliance with the subset standard can also be achleved with a modest amount of reprogramming. This section has not focused on the mechanics through which the computerlzed procedure operates and generates solutions. The intent of this section was to provide a general overview rather than stress programming detalls. For those readers interested in the steps which must be taken in order to use the procedure, two companion reports have been prepared. 3,4 The companion reports consist of step-by-step instructions for using the program (User's Manual) as well as program documentation, flow charts, format statements, sample computer runs, and a complete listing of the FSESCM program (Programmer's Manual).

The program does have several limitations which may be important in certain instances. First, the costing procedure used in the model is limited to the costs of Installing (Including any demolition and removal costs) all possible combinations of the fire safety measures defined in Table 4 of the Fire Zone Safety Evaluation Worksheet. Consequently, any costs which are not construction related (e.g., lost revenues, future operations and maintenance costs and insurance differentials) are not included in the procedure. If these costs are deemed sufficiently important, a life-cycle cost analysis of the alternatives which result from this procedure should be performed. The accuracy of the costs presented by the model should be sufficlent to discriminate among alternative solutions; however, these costs should not be used as a firm figure for actually carrying out the work.

Second, FSESCM does not contain a procedure for estimating the costs of mechanically assisted smoke control systems. Thus, if a transition to the mechanically assisted by zone state 18 desired, the user must input a cost estimate via the CHANGE option (see table 3.2). A simflar limitation exists for the direct exit state for emergency movement routes. The user can, however, input a cost estimate by using the CHANGE option. There are two states listed in Table 4 of the Fire Safety Evaluation Worksheet which FSESCM

TAmerican National Standards Institute, American National Standard Programming Lanugage FORTRAN, ANSI X3.9-1978, New York, 1978 .

2The federal standard for FORTRAN is: U.S. Department of Commerce, National Bureau of Standards, Federal Information Processing Standards Publication 69, September 1980. It 18 Identical to the ANSI standard.

3 R.E. Chapman and W. G. Hall, User's Manual for The Fire Safety Evaluation System Cost Minimizer Computer Program, National Bureau of Standards, NBSIR (in preparation).

${ }^{4}$ R.E. Chapman and W. G. Hall, Programmer's Manual for the Fire Safety Evaluation System Cost Minimizer Computer Program, National Bureau of Standards, NBSIR (In preparation). 
treats as 1mpossible; they are cases where a hazardous area has elther a double or single deficlency outside the fire zone. These states are precluded because the entire cost of upgrading the deficlency is allocated to the fire zone where the deficlency occurs. If a bullding enters with such a set of deficlencles which can not be removed, then the user must preclude all states but the one input for each hazardous area. Since this will affect the set of solutions based on the prespecifled set of design variable qualifiers, 1ts use is not recommended.

Third, given the current procedure for Insuring the compatibility of a set of designs for the entire facility, a limitation of $10 \mathrm{fire} z o n e s$ for any one bullding is imposed. The maximum of 10 can be increased however, by merely increasing one set of storage capacity statements. For some specific uses, the way in which alternative solutions are generated, may not provide enough flexibility. In such a case, a modification to the program code will be required. Persons wishing to modify the way in which the alternative solutions are generated should carefully follow the directions given in the Programmer's Manual.

Although the procedure described in this report focuses on the 1981 edition of the Life Safety Code, it 18 natural to expect that some changes w111 occur as the code is perlodically revised. Any changes whlch would occur in future editions of the Life Safety Code w1ll thus entall changes to the FSESCM computer program. The nature of the change will determine the ease with which program modifications can be made. At this time three types of changes are envisioned. In an increasing order of complexity these changes are: (1) Increasing or decreasing one or more of the state values; (2) adding a new state to a given building safety feature; (3) adding a new bullding safety feature. (Although shortcuts may be possible, decisions to delete a state or a bullding safety feature would be of a similar level of complexity as those changes denoted as (2) and (3), respectively.) The way in which each change can be incorporated into the FSESCM computer program is discussed in detall in the Programmer's Manual. The discussion which follows is intended to 1llustrate the nature of the change without stressing programming detalls.

Modifying the program to handle a change in one or more of the state values is a straight-forward operation. Since the state values may affect one or more of the safety requirements, however, it may be necessary to revise both the counterparts of Table 4 of the F1re Zone Safety Evaluation Worksheet and Table 6. (Both are stored within the program.) It is also necessary to check if any interdependencies among bullding safety features are affected and if so adjust them to reflect the new value(s). 
If a new state 18 added to the system, then Table 4 and Table 6 must be revised as before. It w1ll also be necessary to add the new state name to the list used for table headings and solution labels. It w11 also be necessary to check if elther a new interdependency comes into play or the relationship specified in an existing one requires modification. The addition of a new state w11 also affect the logic of the program; in particular, the way in which the first class of alternative solutions is generated. The nature of the change relates to an iterative scheme known as looping. Depending on the bullding safety feature, 1t may also be necessary to change the dimensions of certain arrays. If a new interdependency comes into play then additional logic must be provided to insure that all penalties or bonuses are properly recorded.

The addition of a new bullding safety feature affects not only Tables 4 and 6 but also Table 5 since the means for computing the safety score provided within the fire zone must be specified. The generation of the first class of alternative solutions will be affected significantly. The generation of the second class, design equivalent solutions, may also be affected since it may be desirable to add two or more states for this feature to the ones listed in table 3.4 in the next section. Arrays will definitely have to be redimensioned and logic to check for interdependencies or pecularities of the new building safety feature will have to be added.

The previous discussion has focused on the equivalency methodology for health care facilities. There are, however, other equivalency methodologies currently under development. These methodologies treat occupancies which differ from those specified in chapters 12 and 13 of the Life Safety Code. At the present time, the methodology which is nearest to completion deals with board and care homes. 1 This system represents only a slight variation from the one considered in this report. Therefore it is reasonable to expect that the FSESCM computer program could be modified to handle the new system once it has been formally adopted 1nto the Life Safety Code. A preliminary analysis of the program indicates that 1t would be preferable to design a new procedure which, if desired, could handle this occupancy as a special case. The reasons for not recommending the board and care home methodology for incorporation into the FSESCM program are twofold. F1rst, the methodology for board and care homes is in reality three evaluation systems. There are separate worksheets for small dwelling units, large residential facillties and apartment bulldings. Each worksheet stresses different building safety features and hence would have different data collection needs. Second, the concept of design equivalent solutions would have to be redefined. The two issues just mentioned would require the design of a procedure which was highly modular so that components for each facility type would plug into a main

\footnotetext{
1H. E. Nelson, et al., Fire Safety Evaluation System for Board and Care Homes, National Bureau of Standards, NBSIR (in preparation).
} 
program which controls the flow of information in solving the problem. Although the FSESCM computer program is modular in its structure, which facilitates incorporating those modifications needed to handle the three types of changes mentioned earlier, there is not a good match betwewen the types of modules which make up the FSESCM and those needed to handle board and care homes. If a decision is made to build a model which handles board and care homes, it would be possible to include as options the opportunity for handing hospitals and nursing homes. Much of the current procedure could then be "plugged in" to handle these options. Although the programming effort to bulld such a procedure would be significant, the basic method of approach would be Identical to that of the FSESCM.

\subsection{THE PROGRAM OUTPUT AND ITS INTERPRETATION}

The information printed out by the FSESCM program fits into three major classes, which are summarized schematically in figure 3.2 .

The first class consists of background information and includes a title page and Tables 1, 6 and 4 of the Fire Zone Safety Evaluation Worksheet. The title page also serves as a malling label and ldentifles the appropriate staff member to contact in the event that a problem is encountered in analyzing the facility. The three tables from the worksheet are included in order to show how the occupancy risk factors are used to calculate the general safety requirement, what values for containment, extinguishment and people movement safety are required for equivalance, and the full range of state values which contribute toward fire zone safety.

The second class consists of reference data and solutions. This class is output for each fire zone. These outputs consist of a summary of all data input for the fire zone, the estimated costs of moving from the input state to each potential retrofit, and all distinct solutions generated for the fire zone. The input summary provides the user with a concise statement of the data used in setting up the problem for solution. It provides the user an opportunity to check the correctness of any values input as well as a means of differentiating among several runs for the same fire zone. This summary shows the location of the fire zone, the number of patients and the appropriate set of occupancy risk factors for the fire zone under study. Data on each of the 13 bullding safety features are then printed out. These data show the input and prescriptive state and the number of elements which must be upgraded in order to move to a higher state. The costs of moving from the input state to all potential retrofits are then presented. This output includes the location of the fire zone and three types of construction cost modifiers. The modiflers are needed because all costs stored within the FSESCM program reflect the cost of installing a particular element (e.g., installing a class $B$ door in a hazardous area) in the greater Washington, D. C. metropolitan area during the summer of 1981. Consequently, it is not only necessary to adjust 
for regional price differences in the markets for labor services and bullding materials, but also to adjust for cost growth over t1me. All three of these cost factors are readily avallable from construction industry publications. Each of the 13 bullding safety features is then printed out. The data show the input and prescriptive states and the estimated cost of going to each potential retrofit. The cost of prescriptive compliance for the fire zone is also shown as a basic reference point. The fire zone summary report is then output. This report shows each distinct solution generated as a line of output. Each of the first 13 columns corresponds to a bullding safety feature. The fourteenth through seventeenth give the surplus over each of the four safety requirements. The elghteenth column is the estimated cost to comply. In order to easily identify a particular solution, and for ease in differentiating among solutions, the state name is printed beneath each of the 13 building safety feature column headings. The state names closely resemble (and hence can be easily matched to) the labels in Table 4 of the Fire Zone Safety Evaluation Worksheet. The order in which the solutions are output is based on the 40 design classifications. The design variable qualifiers used in establishing the 40 design classifications and the order in which they are generated is shown in table 3.4. All solutions are printed out in ascending order of cost within a design classification. The program then outputs the solution(s) for the next design classification for which at least one solution was generated until the list is exhausted. The prescriptive solution is then output. Three other groups of solutions are also output. They are: (1) solutions which have no deficiencies in hazardous areas but do not belong to one of the design classifications; (2) solutions which have a single deficiency in a hazardous area; and (3) solutions which have a double deficiency in a hazardous area.

The third class of outputs consists of the best solutions by design classification for the entire building. The design classification solutions are generated and stored for each fire zone. Once all data on the fire zones have been input and analyzed, all solutions are screened. The ones which match the prespecified set of design variable qualifiers are identifled. If every fire zone input has at least one solution which was identified as a member of the design classification under consideration, then a solution for the entire building is generated. This printout gives the design variable qualifiers, the total cost of retrofitting the bullding for this design classification and the total cost of prescriptive compliance for the building under study. The prescriptive solution serves as a bench mark for comparison. The design classification solutions are printed out in ascending order to estimated retrofit cost for the entire building to facilitate comparison among competing design alternatives. With two exceptions, a separate heading for the floor and fire zone number, the column headings for the output are the same as those for the fire zone summary report. In order to facilitate the identification of each solution, the state names for each of the 13 building safety features are printed out as are the surpluses and retrofit cost for each fire zone. Each fire zone takes up one line in the printout. If one or more fire zones did not contain this design class, no printout for the entire bulding is generated. Should the user wish such a retrofit, it would be necessary to synthesize it from the individual fire zone printouts. 


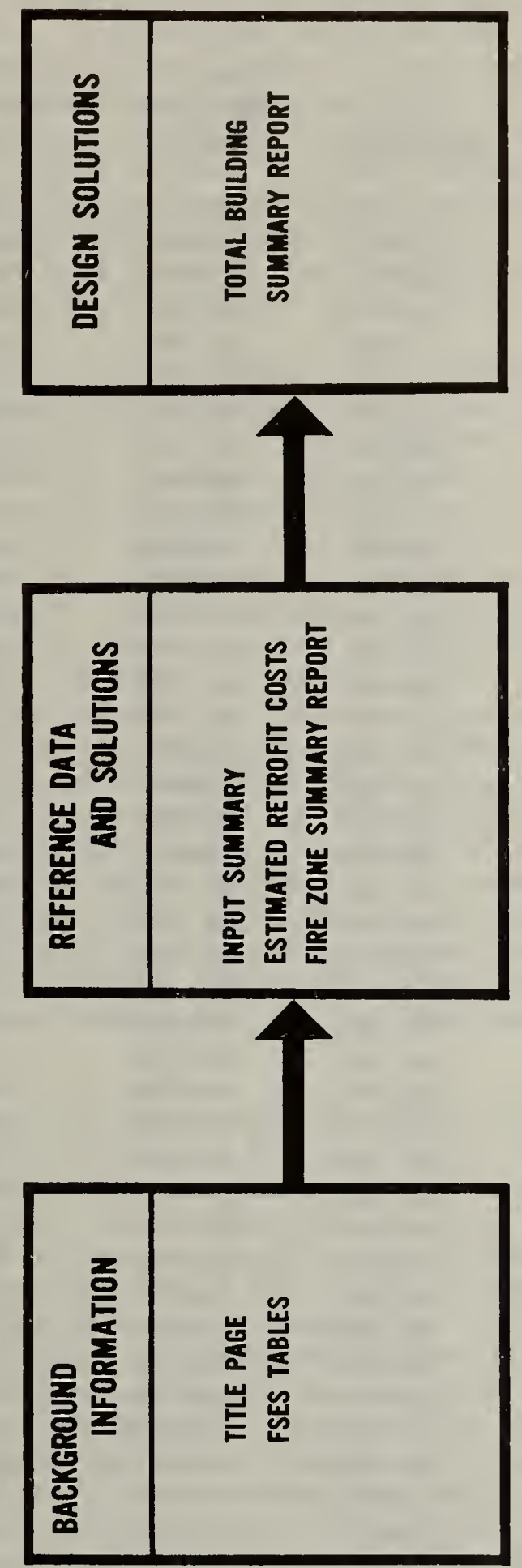


Table 3.4 Design Varlable Qualiflers Used in Establishing the 40 Design Classifications

\begin{tabular}{|c|c|c|c|c|c|}
\hline $\begin{array}{c}\text { Hazardous } \\
\text { Areas }\end{array}$ & Construction & $\begin{array}{c}\text { Zone } \\
\text { Dimensions }\end{array}$ & $\begin{array}{l}\text { Emergency } \\
\text { Movement } \\
\text { Routes }\end{array}$ & $\begin{array}{l}\text { Smoke } \\
\text { Detection } \\
\text { and Alarm }\end{array}$ & $\begin{array}{l}\text { Automatic } \\
\text { Sprinklers }\end{array}$ \\
\hline NO DEF & RESIST & NO DED & HOR*EX & INPUT & INPUT \\
\hline NO DEF & PROTECT & NO DED & HOR*EX & INPUT & INPUT \\
\hline NO DEF & RESIST & $\mathrm{DED} * 30$ & HOR*EX & INPUT & INPUT \\
\hline NO $\mathrm{DEF}$ & PROTECT & $\mathrm{DED} * 30$ & $\mathrm{HOR}^{*} \mathrm{EX}$ & INPUT & INPUT \\
\hline NO DEF & RESIST & NO DED & NO $H * E$ & INPUT & INPUT \\
\hline NO DEF & PROTECT & NO DED & NO $\mathrm{H} * \mathrm{E}$ & INPUT & INPUT \\
\hline NO DEF & RESIST & $\mathrm{DED} * 30$ & NO $\mathrm{H} * \mathrm{E}$ & INPUT & IUPUT \\
\hline NO DEF & PROTECT & $\mathrm{DED} * 30$ & NO $H * E$ & INPUT & INPUT \\
\hline NO DEF & RESIST & NO DED & $\mathrm{HOR}^{\star} \mathrm{EX}$ & CORHAB & INPUT \\
\hline NO DEF & PROTECT & NO DED & $\mathrm{HOR} * \mathrm{EX}$ & CORHAB & INPUT \\
\hline NO DEF & RESIST & $\mathrm{DED} * 30$ & $\mathrm{HOR} * \mathrm{EX}$ & CORHAB & INPUT \\
\hline NO DEF & PROTECT & $\mathrm{DED} * 30$ & HOR*EX & CORHAB & INPUT \\
\hline NO DEF & RESIST & NO DED & NO $\mathrm{H}^{*} \mathrm{E}$ & CORHAB & INPUT \\
\hline NO DEF & PROTECT & NO DED & NO $H * E$ & CORHAB & TNPUT \\
\hline NO DEF & RESIST & $\mathrm{DED} * 30$ & NO $\mathrm{H}^{*} \mathrm{E}$ & CORHAB & INPUT \\
\hline NO DEF & PROTECT & $\mathrm{DED} * 30$ & NO $H * E$ & CORHAB & INPUT \\
\hline NO DEF & RESIST & NO DED & $\mathrm{HOR} * \mathrm{EX}$ & INPUT & CORHAB \\
\hline NO DEF & PROTECT & NO DED & $\mathrm{HOR} * \mathrm{EX}$ & INPUT & CORHAB \\
\hline NO DEF & RESIST & $\mathrm{DED} * 30$ & $\mathrm{HOR} * \mathrm{EX}$ & INPUT & CORHAB \\
\hline NO DEF & PROTECT & $D E D * 30$ & $\mathrm{HOR}^{* \mathrm{EX}}$ & INPUT & CORHAB \\
\hline NO DEF & RESIST & NO DED & NO $\mathrm{H} * \mathrm{E}$ & INPUT & CORHAB \\
\hline NO DEF & PROTECT & NO DED & NO $H * E$ & INPUT & CORHAB \\
\hline NO DEF & RESIST & $D E D * 30$ & NO $\mathrm{H} * \mathrm{E}$ & INPUT & CORHAB \\
\hline NO DEF & PROTECT & $\mathrm{DF} D * 30$ & NO $H^{*} E$ & INPUT & CORHAB \\
\hline NC DEF & RESIST & NO DED & $\mathrm{HOR} * \mathrm{EX}$ & TTLZON & INPUT \\
\hline NO DEF & PROTECT & NO DED & $\mathrm{HOR}^{*} \mathrm{EX}$ & TTL,ZON & INPUT \\
\hline NO DEF & RESIST & $\mathrm{DED} * 30$ & $\mathrm{HOR}^{*} \mathrm{EX}$ & TTLZON & INPUT \\
\hline NO DEF & PROTECT & $\mathrm{DED} * 30$ & $\mathrm{HOR} * \mathrm{EX}$ & TTLZON & INPUT \\
\hline NO $\mathrm{DEF}$ & RESIST & NO DED & NO $\mathrm{H} * \mathrm{E}$ & TTLZON & INPUT \\
\hline NO DEF & PROTECT & NO DED & NO $H * E$ & TTLZON & INPUT \\
\hline NO DEF & RESIST & $\mathrm{DED} * 30$ & NO $H^{*} E$ & TTLZON & INPUT \\
\hline NO DEF & PROTECT & $\mathrm{DED} * 3 \mathrm{C}$ & No $H * E$ & TTLZON & INPUT \\
\hline NO $\mathrm{DEF}$ & RESIST & NO DED & HOR*EX & INPUT & TTLBLD \\
\hline NO $\mathrm{DEF}$ & PROTECT & NO DED & $\mathrm{HOR} * \mathrm{EX}$ & INPUT & TTLBLD \\
\hline NO DEF & RESIST & $\mathrm{DED} * 30$ & HOR*EX & INPUT & TTLBLD \\
\hline NO DEF & PROTECT & $\mathrm{DED} * 30$ & $\mathrm{HOR}^{*} \mathrm{EX}$ & INPUT & TTLBLD \\
\hline NO DEF & RESIST & NO DED & NO $\quad H^{*} \mathrm{E}$ & INPUT & TTLP.LD \\
\hline NO DEF & PROTEC & NO DED & NO $H^{*} E$ & INPUT & TTLBLD \\
\hline NO DEF & RESIST & $\mathrm{DED} * 30$ & NO $H^{*} E$ & INPUT & TTLBLD \\
\hline NO DEF & PROTEC & $\mathrm{DED} * 30$ & NO $H * E$ & INPUT & TTLBLD \\
\hline
\end{tabular}


The purpose of this section is to demonstrate how one would apply the FSESCM program to a typical hospital. The hospital analyzed in the case study is thought to be typical of many facilities since it consists of the original (1917) building and a post World War II addition (1959). The layout of the patient room floors is shown in figure 3.3; it is treated as a single fire zone. The overall length of the fire zone is approximately $180 \mathrm{feet}$. The exterior bearing walls of the original structure do, however, provide an excellent opportunity for installing a horizontal exit to reduce the overall dimensions of the fire zone. Each floor of the facility contains 22 patient rooms and covers a total floor area of 11,000 square feet.

As mentioned earlier, the data from the FSESCM Cost Estimation Worksheet (exhib1t 3.1) are reviewed and pleced together unt11 they roughly resemble the retrofits specified in table 3.3. The data are then used to set up the problem for solution by the FSESCM program. Four types of output information are shown as exhibits 3.2 through 3.9. Each exhibit is divided into two parts. Part A is a sample output and Part B is an interpretation of the information printed out. The outputs for which samples are provided are: the input summary (exhibit 3.2); (2) the summary of estimated retrofit costs (exhibit 3.3); (3) the fire zone summary report (exhibit 3.4 ); and (4) the total bullding summary report (exhibits 3.5 through 3.9 ). No samples are shown for the outputs described earlier as background information (the title page and Tables 1, 6 and 4 from the Fire Zone Safety Evaluation Worksheet) because 1t was felt the information contained on them was self explanatory. It is important to point out that exhibits 3.2 through 3.9 are samples selected to 1llustrate specific points and as such do not constitute the complete output for the building being analyzed. For example, exhibits 3.2 through 3.4 are the outputs associated with the patient room floors (floors 3 through 9) and hence do not contain laboratories, heavy equipment areas, or other areas which may call for special treatment. Those readers wishing to see the full set of inputs and outputs for the bullding analyzed are referred to the User's Manual.

For purposes of 1llustration, the total building summary reports presented as exhibits 3.5 through 3.9 will be analyzed in some detall. The relative costs, as a percentage of the prescriptive compliance costs, are shown in figure 3.4 . This figure shows that the range of cost savings is quite dramatic, with the best solution from among the 40 design classifications costing only 10 percent of the prescriptive compliance solution. The solutions shown in figure 3.4 were selected to illustrate another point, namely that the requirement for the inclusion of a high cost option (e.g., the installation of an exit stairwell to remove a dead end corridor charge) can be accomplished at a significant savings in overall compliance costs. This result is due to the way in which the procedure upgrades the bullding safety features not constrained by the design variable qualifiers. There are clrcumstances under which the additional cost of compliance can be traced to a particular option, however. For example, the best solution for the building, presented as exhibit 3.5 (bar A on figure 3.4 ), costs slightly over $\$ 30,000$. If we now require smoke detection and alarm in all corridors and habitable spaces, hold all other 


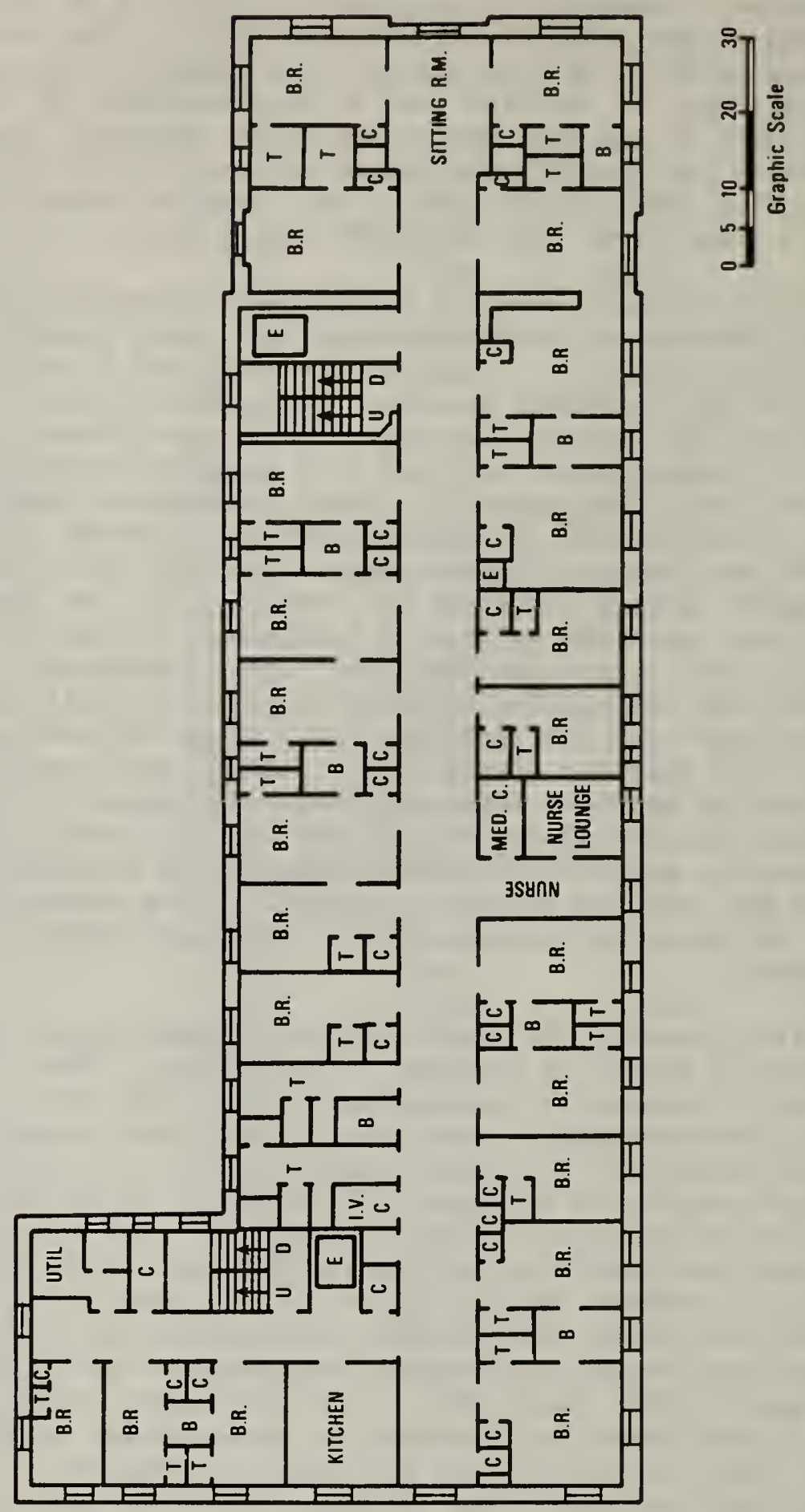


design variable qualifiers constant, and let the remaining building safety features be upgraded in the most cost-effective manner, the total cost for the building rises to around $\$ 110,000$ (bar B on figure 3.4 ). In this case, the additional cost of compliance is due almost entirely to the installation of smoke detection and alarm equipment. Requiring smoke detection and alarm in the total space (bar $C$ on figure 3.4) has a similar effect. This imples that some care should be exercised in deciding on whether to cover corridors and habitable spaces only or to go for covering the total space. A similar. conclusion results if automatic sprinkler systems are considered. In exhibit 3.8 (bar D on figure 3.4), the dead end corridor charge on floors 3 through 918 removed through the installation of an exit stairwell. In this case the cost of compliance of $\$ 215,000$, is approximately 30 percent less expensive than the prescriptive compliance solution. Another important facior concerns the surpluses over the 4 safety requirements. In almost all cases the fire zones within a design classification exceed the requirements by several points. The surpluses therefore serve both as a buffer against future changes in safety requirements and provide information which may be useful in choosing among retrofit packages which are close in cost to each other. 
Exhibit 3.2 Sample Output Sumarizing the Data Input for a Typical Fire Zone Part A: Printout

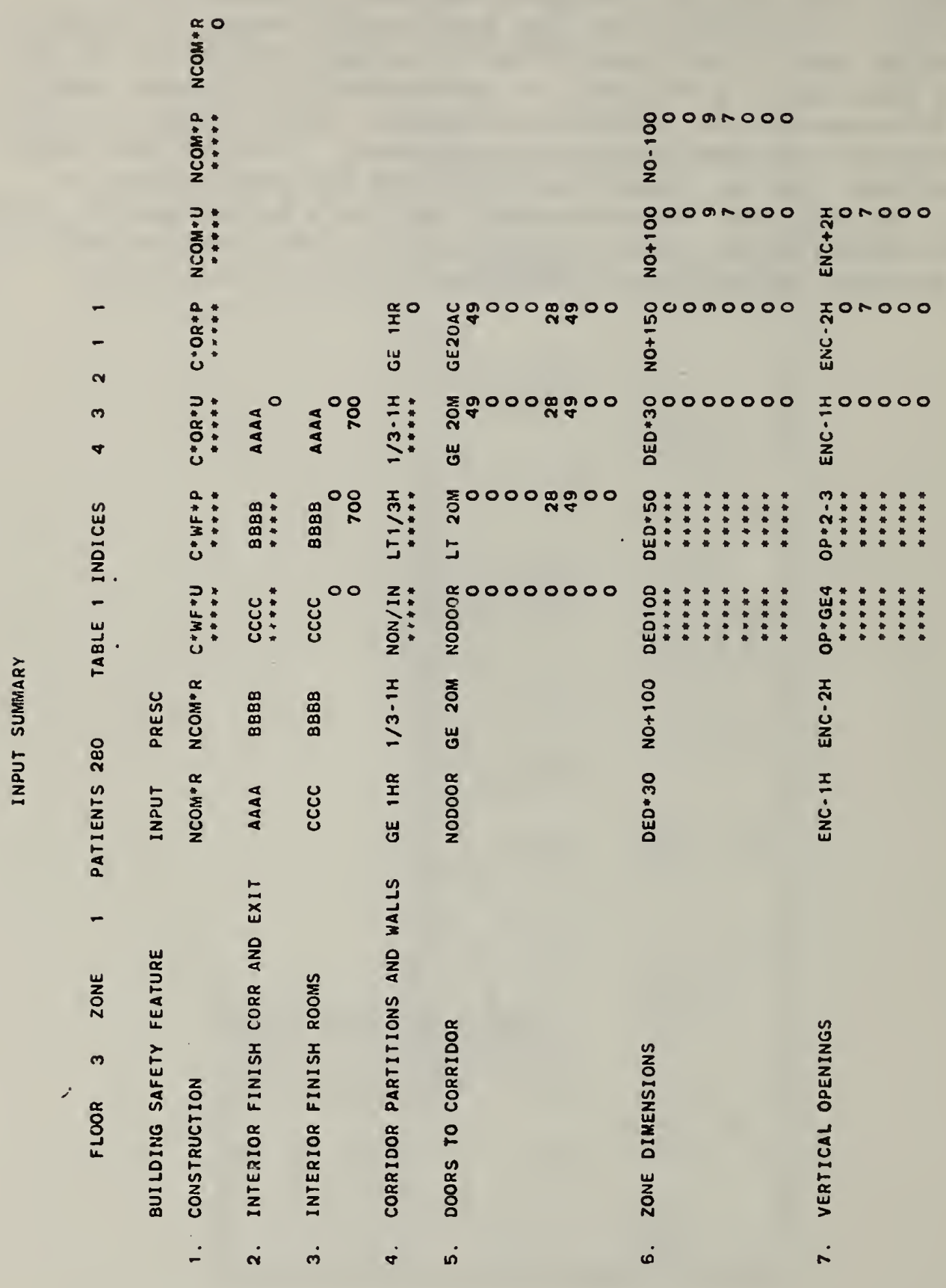


Exhlb1t 3.2 Sample Output Summarizing the Data Input for a
Typical Fire Zone

Part B: Description

The purpose of this printout is to summarize the data used in setting up the problem for solution. It is also useful in distinguishing among runs when a sensitivity analysis is performed. The first descriptive line shows the location of the fire zone, the number of patients and the state numbers for Table 1 of the Fire Zone Safety Evaluation Worksheet. In this case the zone aggregates data on floors 3 through 9 of the facllity. Each of the 13

bullding safety features is then 11sted. The two columns to the right of the bullding safety feature name show the input and prescriptive states. Up to 7 columns are then used to show the number of elements which must be upgraded in order to move to a higher state. The actual element counts consist of from 1 to 8 rows depending on the bullding safety feature and 1ts condition. If the bullding safety feature was input in the highest state, then only one row is used regardless of the number of elements which can be treated. If the bullding safety feature was not in the highest state, then each row corresponds to a particular element. For example, the two rows associated with interior finish in rooms correspond to the square feet of walls and cellings which would have to be coated with retardant in order to move to Class $B$ or Class A flame spread ratings. In interpreting the values, it is necessary to note that the symbol $\star \star \star \star \star \star$ Indicates that the state whose name appears above it not a permissible retrofit. This may result because the state 18 below the input and hence would result in a regression in score (e.g., construction is already in the highest state) or it is precluded on engineering grounds. The states which are permissible have elther a value of zero or some positive integer recorded. For example, 0 square feet of walls and 700 square feet of cellings must be coated with retardant in order to move to elther the Class B or Class A flame spread rating for interior finishes in rooms. The second page of the printout consists of data on bullding safety features 8 through 13. These data are not reproduced since their interpretation is the same as given above. 
Part A: Printout

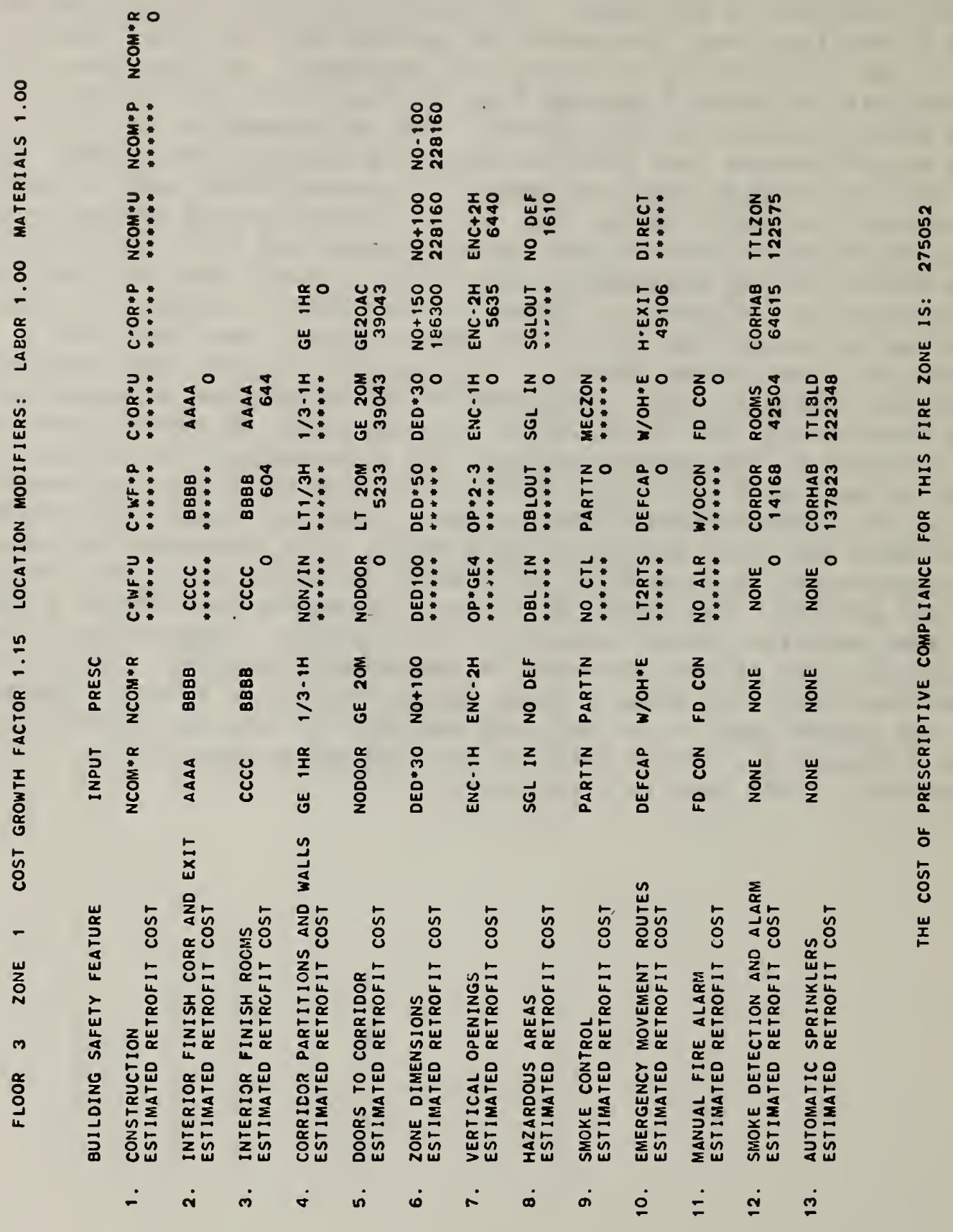


Exhibit 3.3 Sample Output Showing the Estimated Cost for Each Potential Retrofit for a Typical Fire Zone

\section{Part B: Description}

This printout shows the estimated costs for all potential retrofits. The first descriptive line shows the zone location and the values of each of the three construction cost modifiers. For this case, costs have increased 15 percent over those experienced during the summer of 1981 in the Washington, D.C. area. Each of the 13 building safety features is then listed. The two columns to the right of the building safety feature name show the input and prescriptive states. Up to 7 columns are then used as labels for each possible state within a building safety feature. The line immediately beneath the building safety feature name bears the title "Estimated Retrofit Cost"; it lists the estimated cost for each potential retrofit. In interpreting the values, it is necessary to note that the symbol $* \star \star \star * *$ indicates that the state whose name appears above is not a permissible retrofit; it is assigned an arbitrarily high cost to prevent its occurence. This may result because the state is below the input and hence would result in a regression in score (e.g., construction is already in the highest state) or it is precluded on engineering grounds (e.g., mechanically assisted smoke control by zone). Those states which are permissible have either a value of zero or some positive integer recorded. In each case, the cost of remaining in the input state is recorded as zero. If desired, this assumption can be modified through use of the CHANGE option. It may also be possible to move to a higher state for zero cost if the change is not construction related. The remainder of the costs are based on the expected cost of upgrading all critical elements recorded in the previous exhibit. The bottom line of the printout is the estimated cost of prescriptive compliance. Since some states may already exceed their prescriptive level, no cost is incurred for that building safety feature. For all other cases, the cost is the sum of the costs of the prescriptive compliance state listed under the heading "PRESC". 
Exh1b1t 3.4 Sample output Showlng the Solutions Generated for a Typ1cal P1re Zone

Part A: Printout

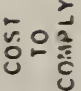

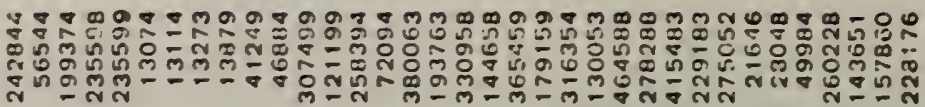

胥识

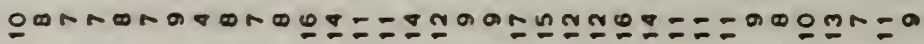

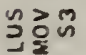

突㐫心

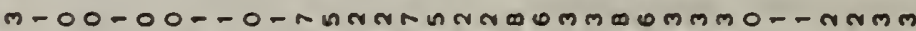

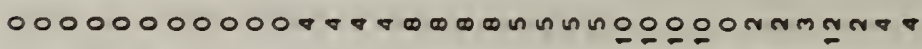

zón

$\frac{\alpha}{\frac{\pi}{\alpha}}$

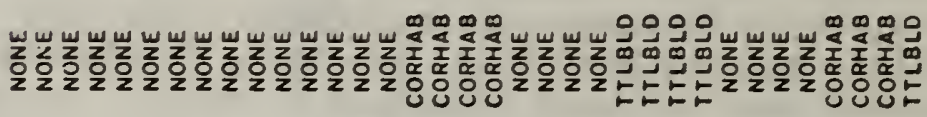

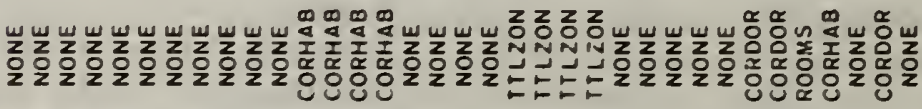

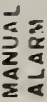

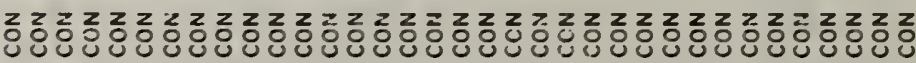

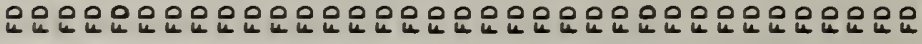

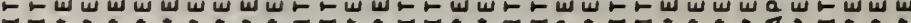

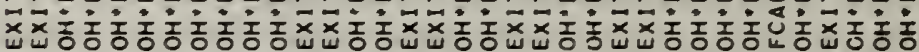

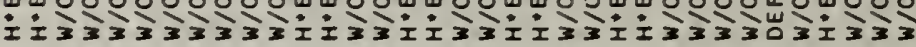

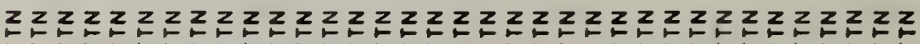

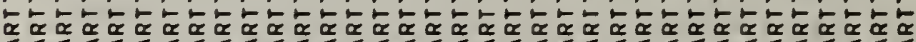

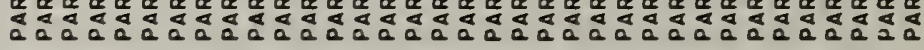

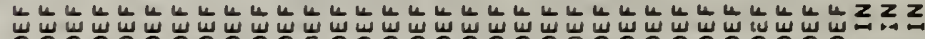

(n) 崖全宸

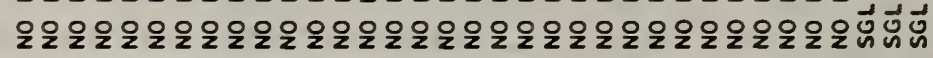

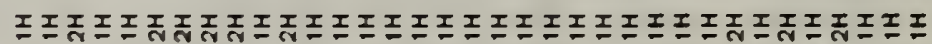

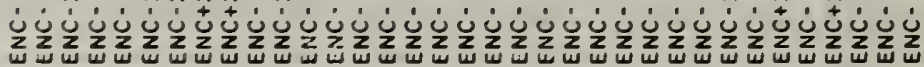

告

㲾

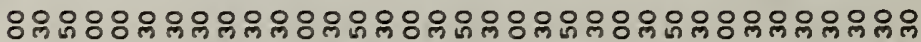

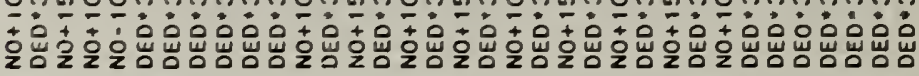

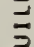

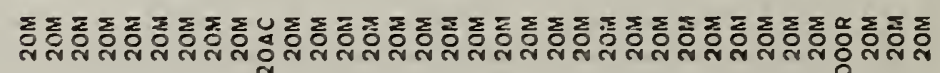

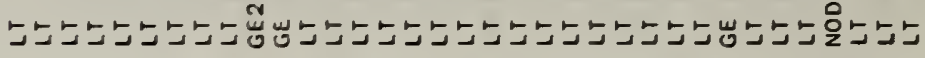

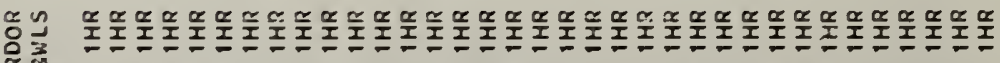

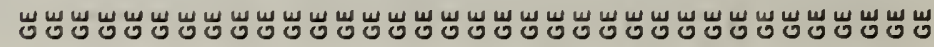

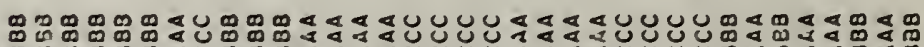

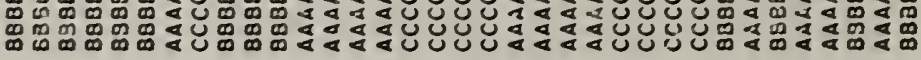




\section{Exh1b1t 3.4 Sample Output Showing the Solutions Generated for a Typlcal F1re Zone}

\section{Part B: Descr1ption}

This printout shows all of the distinct solutions generated for the fire zone under study. The first descriptive line shows the fire zone location. Each of the 13 bullding safety features are then listed followed by the 4 safety requirements. The estimated cost to comply is presented in the last column. The name of the post retrofit state for each of the 13 bu1lding safety features are 11sted beneath the appropriate column heading. Each solution takes up one line of the output. The surpluses over the required score for containment, extingulshment, people movement and general safety are then recorded. The order in which the solutions are output is based on the 40 design classifications. The following bullding safety features are used to define the design classifications: (1) construction; (2) zone dimensions; (3) hazardous areas; (4) emergency movement routes; (5) smoke detection and alarm; and (6) automat1c sprinklers. All solutions are ranked and printed out in ascending order of cost. The program then outputs the solution(s) for the next design classification for which at least one solution was generated unt1l the list is exhausted. The prescriptive solution is then output. Note that in this case, the prescriptive solution shows surplus scores on all 4 safety requirments; the estimated cost of prescriptive compliance $18 \$ 275,052$. The score surpluses are due to some of the lnput states already exceeding thelr prescriptive values. Solutions which do not fit a design classification are then ranked and printed out according to whether they have no deficlencles, a single deficlency, or a double deficlency in hazardous areas. 
Exhib1t 3.5 Sample Output Showing the Best Comb1nation of Design Equivalent Solutions

Part A: Printout

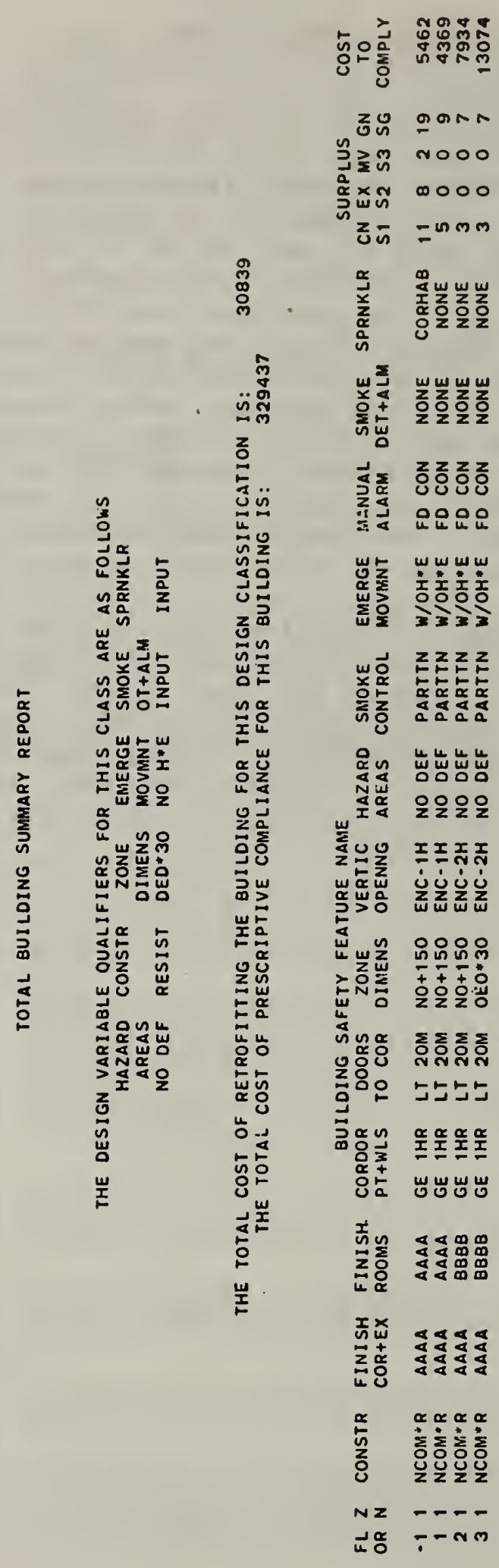




\section{Exhibit 3.5 Sample Output Showing the Best Combination of Design}

Equivalent Solutions

Part B: Description

This printout shows the best solution for the entire building from among the 40 design classifications. The first descriptive heading shows the design variable qualifiers for this design classification. The total cost of retrofitting the entire building to this design classification is then given followed by the cost of prescriptive compliance. In this case the total cost is aproximately 10 percent of that associated with prescriptive compliance. Information on the location of the fire zone, the post retrofit state for each of the 13 bullding safety features, the surplus over each of the 4 safety requirements, and the estimated cost to comply are then printed out. Each fire zone takes up one line of output. The solutions for the fire zones are based on the least cost solution from within the design classification under consideration. If, as in this case, one of the design variable qualifiers entered in a state above that which appears in the heading, an artificial solution is created. Thus although the qualifier for zone dimensions is a dead end greater than 30 feet, since the first three fire zones entered with no dead ends, they are included as an artificial solution within this design classification. This approach is taken because the objective of the design classifications is to have a compatible set of retrofits. Since the existing condition within the building was acceptable (1.e., a mixture of dead ends on floors 3 through 9 and no dead ends in the basement, first and second floors), not changing one of the building safety features across all zones should not affect the acceptability of the design. The classifications are, however, based on a worst case scenario. Thus if a dead end resulted in any fire zone, no artificial solution would be generated indicating a "no dead end" situation. 
Exh1b1t 3.6 Sample Output Show1ng Des1gn Equivalent Solutions Based on Smoke Detection and Alarm in Corridors and Habitable Spaces

Part A: Printout

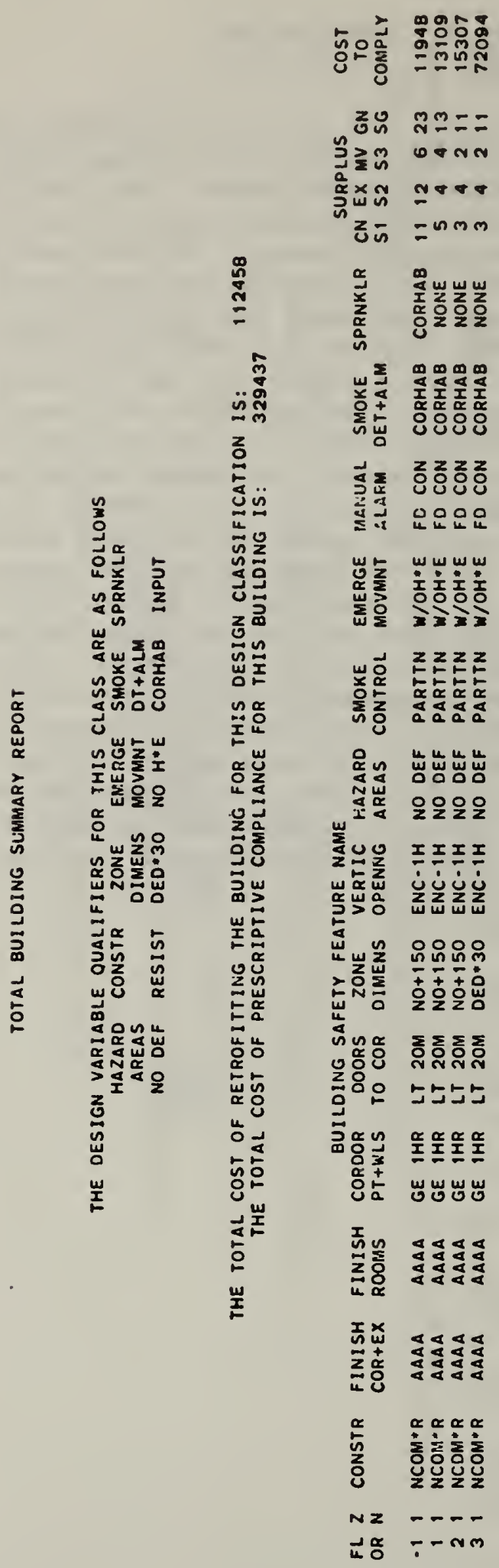


Exhibit 3.6 Sample Output Showing Design Equivalent Solutions Based on Smoke Detection and Alarm In Corridors and Habitable Spaces

\section{Part B: Description}

This printout shows the best solutions for each fire zone when smoke detection and alarm are required in all corridors and habitable spaces. The total cost of retrofitting the entire building to this design classification is approximately one third that of prescriptive compliance. As in the previous case, an artificial solution has been created for the fire zones in the basement, first and second floors which were input without any dead ends. In addition, the basement floor was input with sprinklers in all corridors and habitable spaces. 


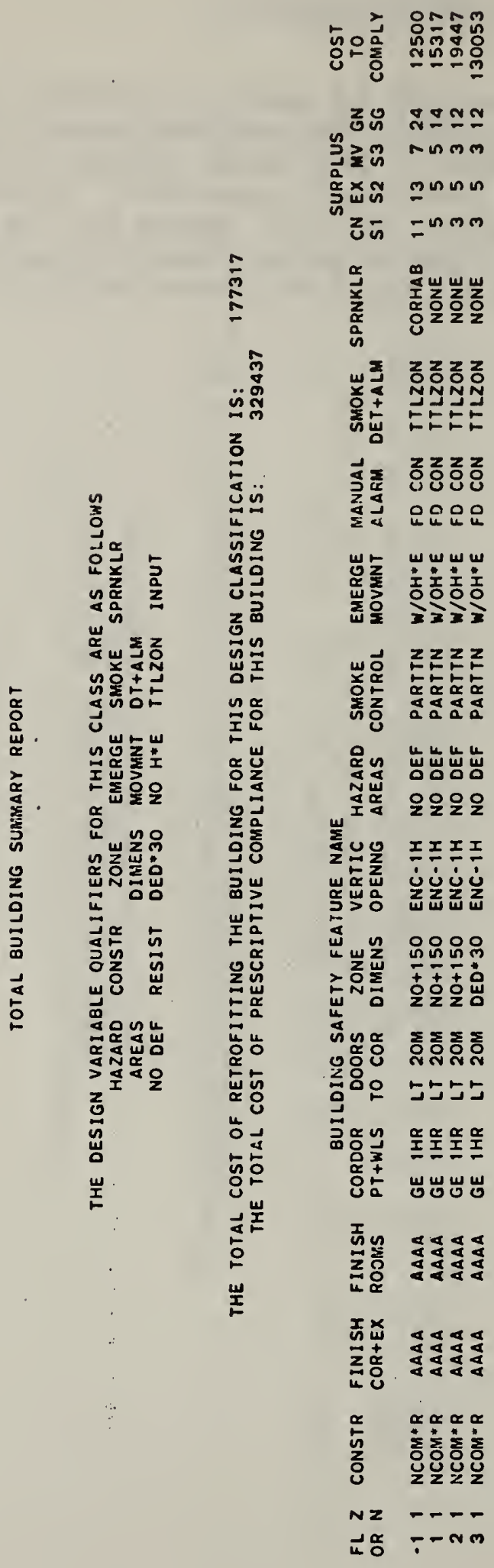


Exhib1t 3.7 Sample Output Showing Design Equivalent Solutions Based on Smoke Detection and Alarm in the Total Space

Part B: Description

This printout shows the best solution for each fire zone when smoke detection and alarm are required throughout the total space. The total cost of retrofitting the entire bullding to this design classification is somewhat more than one half that of prescriptive compliance. Through reference to Table 4 of the Fire Zone Safety Evaluation Worksheet, it can be seen that this movement increases the state value from 4 points to 5 points over the previous case (smoke detection and alarm in all corridors and habitable spaces). An examination of the surplus scores over each safety requirement reveals an average Increase of one polnt. In this case, the additional cost of compliance is due almost entirely to the installation of smoke detection and alarm equipment. If one were to examine the two design classifications where automatic sprinklers were interchanged with smoke detection and alarm, a similar result would occur. Thus careful consideration should be given to any decision which would require detectors or sprinklers in the total space rather than in all corridors and habitable spaces. 
Exh1b1t 3.8 Sample Output Showlng Design Equivalent Solutions Based on No Dead Ends in Corridors

Part A: Printout

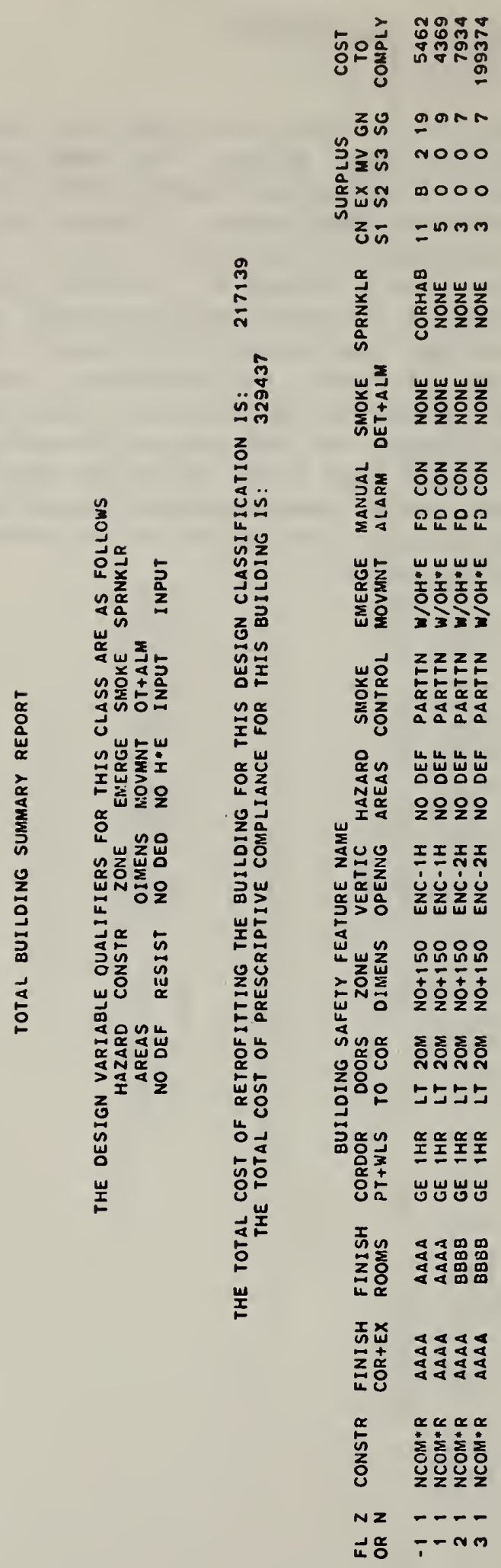


Exhibit 3.8 Sample Output Showing Design Equivalent Solutions Based on No Dead Ends in Corridors

Part B: Description

This printout shows the best solution for each fire zone when no dead ends are permitted. (Recall that a dead end greater than 30 feet existed on floors 3 through 9.) Although the installation of an exit stairwell is quite expensive, the solution produced by the FSESCM program costs about 30 percent less than that associated with prescriptive compliance. This is because the procedure upgrades all bullding safety features which are not constrained by the design variable qualifiers in the most cost effective manner. 
Exhibit 3.9 Sample Output Showing the Detalls of the Prescriptive Compliance Solution

Part A: Printout

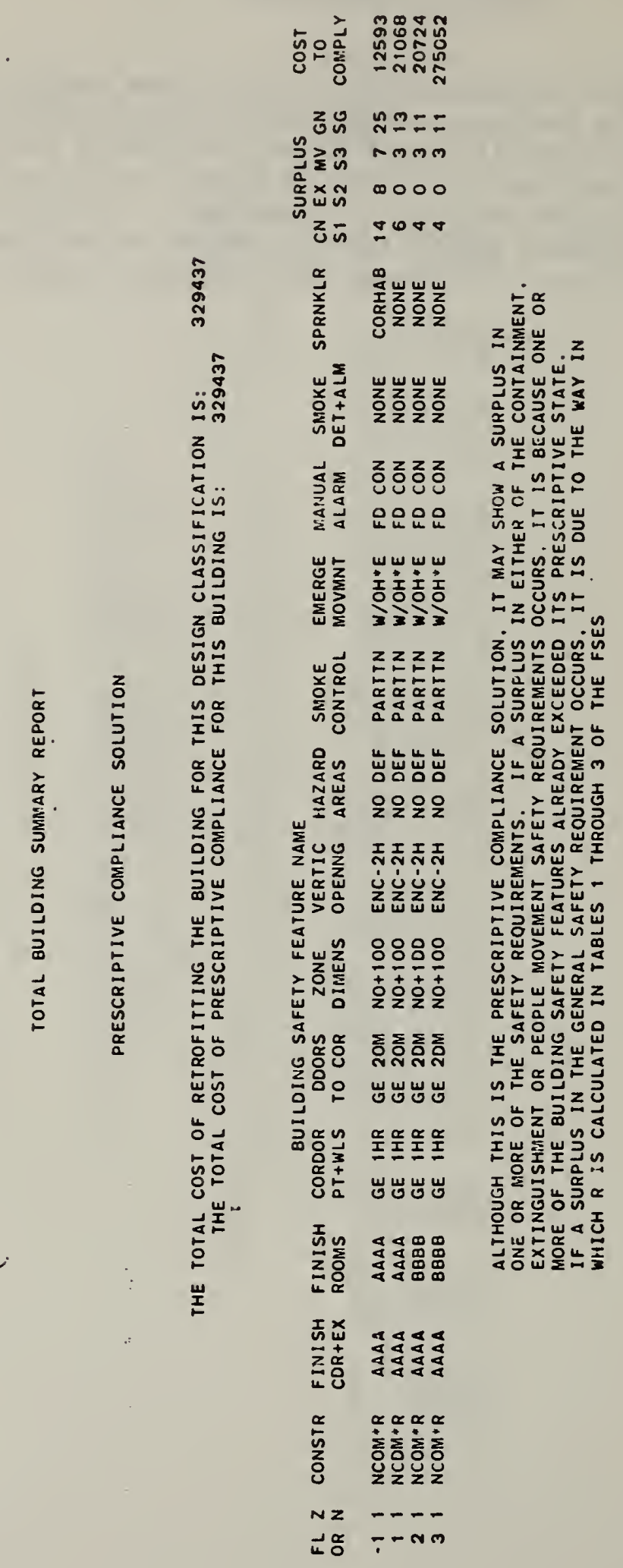


Exhibit 3.9 Sample Output Showlng the Details of the Prescriptive Compliance Solution

\section{Part B: Description}

This printout shows the prescriptive coapliance solution for each fire zone. It is included as a baseline against which all solutions generated by the FSESCM program can be compared objectively. Note that surplus scores are shown for all of the safety requirements. This is because each fire zone as input exceeded one or more of the prescriptive requirements. Although no credit was given for exceeding a requirement prior to the incorporation of the Fire Safety Evaluation Systen 1nto the Life Safety Code, score surpluses are possible if the evaluation procedure of the F1re Safety Evaluation Syste= is used. The values of the surpluses are presented because it is felt that they w11 promote a more meaningful comparison against those solutions based solely on the Fire Safety Evaluation System. 
F1gure 3.4 Alternative Retrofit Packages for the Case Study Bullding

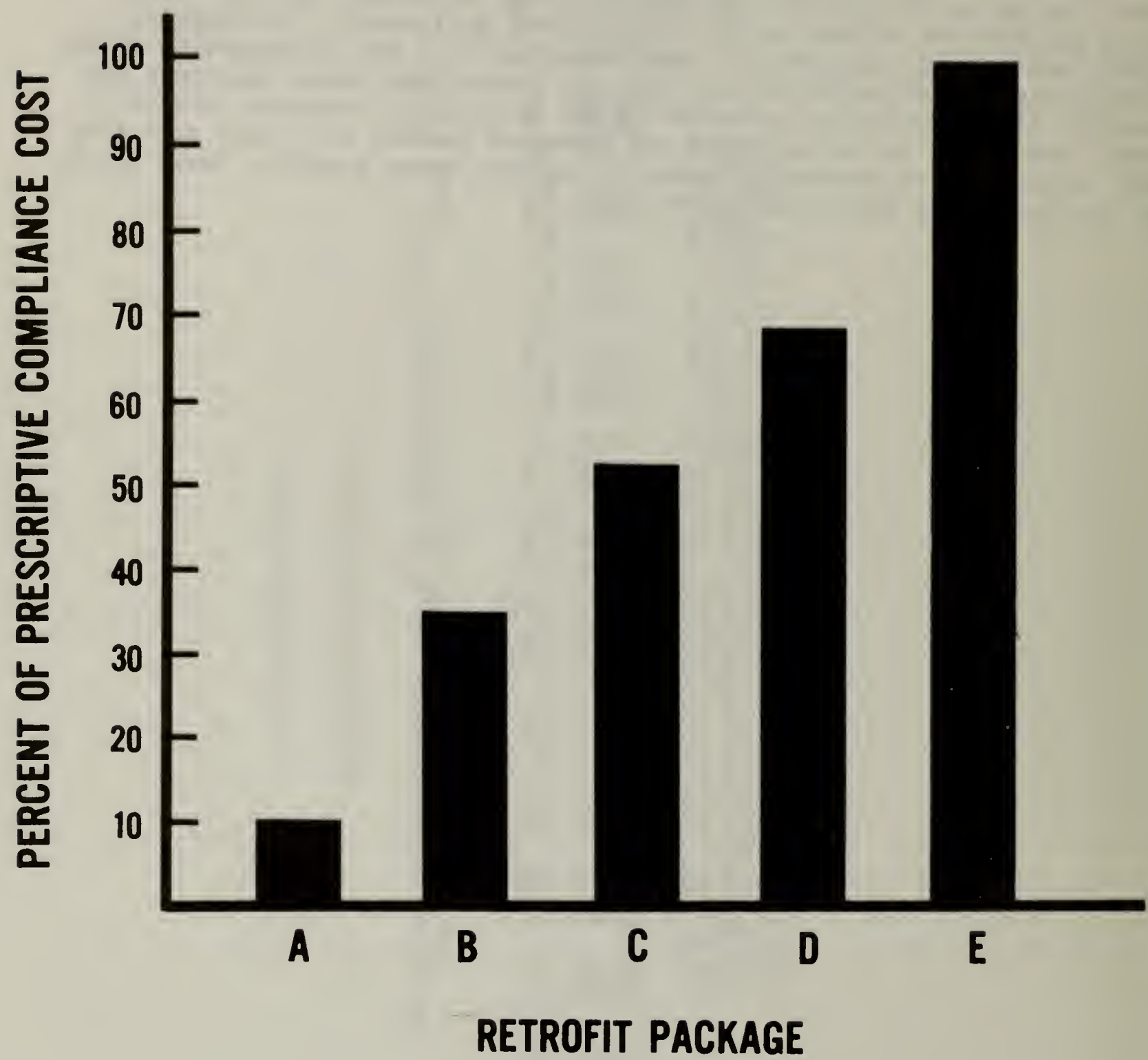




\section{CONCLUDING REMARKS}

The identification of cost-effective levels of fire safety in health care facilities is a major concern to hospital administrators, fire safety engineers, and public policy makers. Rising construction and operating costs coupled with more stringent building codes and continuing advances in medical and building technology have complicated the issue, forcing health care facility administrators to assess carefully the alternative means through which they can design, construct, or update their facilities. The Fire Safety Evaluation System developed by the Center for Fire Research at the National Bureau of Standards, through support from the Department of Health and Human Services, helps decision makers by determining how combinations of several widely accepted fire safety systems can be used to provide a level of safety equivalent to that required by the Life Safety Code.

This study has outlined a computer program which using the Fire Safety Evaluation System as its nucleus, employs mathematical optimlzation techniques to identify the least-cost means of achieving compliance to the Life Safety Code. Since each of the 13 building safety features used in the Fire Safety Evaluation System has a unique value which corresponds to prescriptive compliance, it is possible to quantify the cost savings attributable to the use of a performance-oriented system over that of prescriptive compliance. An indepth analysis of a typical hospital indicated that the use of the Fire Safety Evaluation System Cost Minimizer (FESECM) computer program can result in savings of 50 percent or more over the cost associated with prescriptive compliance to the Life Safety Code.

The procedure used by the FSESCM computer program identifies from 10 to 20 near-optimal compliance strategles. These compliance strategies are generated by using the "optimal" solution as a reference point from which near-optimal solutions can be systematically examined. They are made available to facilitate the design selection process by providing information on relative costs and the opportunity to match common retrofit packages across all fire zones in the building. The use of a predetermined set of compliance strategies results in a considerable saving of time in defining a comprehensive retrofit strategy for the entire building. The compliance. strategies should also simplify the problem of assessing the impacts of nonconstruction costs on the retrofit decision. The FSESCM computer program also contains a series of user options which make it possible to alter the cost of any retrofit, preclude a retrofit, force a retrofit to be included, or demand a level of safety different from that required by the Life Safety Code. 
The results of a case study where a typical hospital was analyzed are an indication of the tremendous potential for reducing costs without compromising the safety and well-belng of persons housed in health care facllities. Although the savings in retrofit costs which will accrue to the nation's stock of health care facilities is substantial, it is expected that savings will vary considerably as a function of the facility type, 1ts condition, and 1ts operational characteristics. Since the design places certain constraints on the retrofit process, the data required from the engineer in the fleld are organized in a manner which explicitly introduced relevant engineering issues into the cost minimization problem. The cost estimates produced by the procedure should permit the engineering staff to quickly identify several candidate retrofit packages which best reflect the specific attributes or pecullarities of the facllity. These candidates should then be assessed via a detalled cost analysis to refine the cost estimates as well as introduce any cost impacts which affect the facllity but are not addressed in the optimization procedure.

The User's Manual contalns a more detalled analysis of the typical hospital discussed in chapter 3. Th1s design was chosen to 1llustrate how the FSESCM computer program would be used to solve actual fire safety problems. Information on the scope and complexity of the retrofit alternatives is obtalned from a series of floor plans for the hospital. Th1s information is used as input for the computer program. 


\section{REFERENCES}

1. American National Standards Institute, American National Standard Programming Language FORTRAN, ANSI X3.9-1978, New York, 1978.

2. Chapman, R.E., P. T. Chen, and W. G. Hall, Economic Aspects of Fire Safety in Health Care Facilities: Guidelines for Cost-Effective Retrofits, National Bureau of Standards, NBSIR 79-1902, Washington, D. C., 1979.

3. Chapman, R.E. and W. G. Hall, User's Manual for The Fire Safety Evaluation System Cost Minimizer Computer Program, National Bureau of Standards, NBSIR (in preparation).

4. Chapman, R.E. and W. G. Hall, Programmer's Manual for the Fire Safety Evaluation System Cost Minimizer Computer Program, National Bureau of Standards, NBSIR (in preparation).

5. Kruger, L.J. and R. M. Patton, "More Fire Safety Can Cost Less," Hospitals, Vol. 51, February 1977, pp 127-132.

6. Lathrop, J.K., editor, Life Safety Code Handbook, National Fire Protection Association, Quincy, Mass., 1981.

7. Lyons, J.W., "Fire Research and Fire Safety: A Status Report on the Situation in the United States," in A. F. Robertson, ed. Fire Standards and Safety, American Society of Testing Materials, Special Technical Publication 614, Philadelphia, 1977.

8. National Fire Protection Association, Code for Safety to Life from Fire in Buildings and Structures, NFPA 101-1973, Boston, 1974.

9. National Fire Protection Association, Code for Safety to Life from Fire in Buildings and Structures, NFPA 101-1980, Boston, 1981 .

10. Nelson, H.E. and A. J. Shibe, A System for Fire Safety Evaluation of Health Care Facilities, National Bureau of Standards, NBSIR 78-1555, Washington, D. C., 1980 .

11. Nelson, H.E., et al., Fire Safety Evaluation System for Board and Care Homes, National Bureau of Standards, NBSIR (in preparation).

12. Sprague, J.G., "A Common Sense Approach Needed in Dealing With Safety," Hospitals, Vol. 51, February 1977, pp. 67-75.

13. U.S. Congress, House, Select Committee on Aging, Subcommittee on Long-Term Care, Tragedy of Multiple Death Nursing Home Fires: The Need for a National Commitment to Safety, September 1976.

14. U.S. Department of Commerce, National Bureau of Standards, Federal Information Processing Standards Publication 69, September 1980 . 
NBS.114A (REV. 2.00$)$

\begin{tabular}{c|c} 
U.3. OEPT. OF COMM. & 1. PUBLICATION OR \\
BIBLIOGRAPHIC DATA & REPORT NO. \\
SHEET (SEe instructions) & NBSIR $82-2600$
\end{tabular}

2. Performing Organ. Report No

3. Publleatlon Date

SHEET (Soe instructions) NBSIR 82-2600

November 1982

4. TITLE AND SUBTITLE

A Cost-Conscious Gulde to Fire Safety in Health Care Facllities

5. $A \cup T H O R(S)$

Robert E. Chapman

6. PERFORMING ORGANIZATION (If Joint or other then NBS, see Instructions)

7. ContracuGrant No.

NATIONAL BUREAU OF STANDARDS

DEPARTMENT OF COMMERCE

WASHINGTON, D.C. 20234

9. SPONSORING ORGANIZATION NAME AND COMPLETE ADDRESS (Street, Clty, Stote, ZIP)

Center for Fire Research

National Englneering Laboratory

National Bureau of Standards

Washington, D. C. 20234

10. SUPPLEMENTARY NOTES

[D Document descrlbes a computer program; SF-185, FIPS Sofiware Summary, is attached.

11. ABSTRACT (A 200-word or less foctual summary of most signiflcont Informatlon. If document Includes a signlflcant blbllogrophy or llteroture survey. mention It here)

Th1s study focuses upon the use of the Fire Safety Evaluation System developed by the Center for Fire Research at the National Bureau of Standards for determining equivalence to the Life Safety Code for health care facilities. The Life Safety Code, a voluntary code developed by the National PIre Protection Association, is a widely used gulde for providing fire safety in bulldings. This study outlines the Fire Safety Evaluation System Cost Minimizer (FSESCM) computer program. The FSESCM program is intended for use as a management tool to identify a series of optimal compliance strategies which are equivalent to the prescriptive provisions of the Life Safety Code in health care facilities. The mathematical optimization techniques which form the basis of the FSESCM program make it possible to quantify the cost savings attributable to the use of the Fire Safety Evaluation System over prescriptive compliance to the Life Safety Code. An In-depth analysis of a typical health care facility is used as a case study to demonstrate that cost savings of 50 percent or more over those assoclated with prescriptive compliance to the Life Safety Code are possible.

12. KEY WORDS (SIX to iwelve entrles; alphobetlcal order; capltallze only proper nomes; and seporate key words by semleolons) Bullding codes; bullding economics; economic analysis; fire safety; health care facilities; hospitals; life safety; mathematical programming; nursing homes; renovation.

13. AVAILABILITY

X] Unlimlied

For Official DIstribution. Do Not Release to NTIS

Order From Superintendent of Documents, U.S. Government Printing Office, Washington, D.C. 20402.

X] Order From National Technical Information Servlce (NTIS), Springfield, VA. 22161
14. NO. OF PRINTED PAGES

65

15. Prlce

$\$ 9.00$ 

